\title{
Creating a More Realistic Idealized Supercell Thunderstorm Evolution via Incorporation of Base-State Environmental Variability
}

\author{
CASEY E. DAVENPORT \\ University of North Carolina at Charlotte, Charlotte, North Carolina \\ CONRAD L. ZIEGLER \\ National Severe Storms Laboratory, and School of Meteorology, University of Oklahoma, Norman, Oklahoma \\ MiCHAEL I. BIGGERSTAFF \\ School of Meteorology, University of Oklahoma, Norman, Oklahoma
}

(Manuscript received 21 December 2018, in final form 27 August 2019)

\begin{abstract}
Convective environments are known to be heterogeneous in both time and space, yet idealized models use fixed base-state environments to simulate storm evolution. Recently, the base-state substitution (BSS) technique was devised to account for environmental variability in a controlled manner while maintaining horizontal homogeneity; BSS involves updating the background environment to reflect a new storm-relative proximity sounding at a prescribed time interval. The study herein sought to assess the ability of BSS to more realistically represent the structure and evolution of an observed supercell thunderstorm in comparison to simulations with fixed base-state environments. An extended dual-Doppler dataset of an intensifying supercell thunderstorm in a varying inflow environment was compared to idealized simulations of the same storm; simulations included those with fixed background environments, as well as a BSS simulation that incorporated environmental variability continuously via tendencies to the base-state variables based on changes in a series of observed soundings. While the simulated supercells were generally more intense than what was measured in the observations, broad trends in reflectivity, vertical velocity, and vertical vorticity were more similar between the observed and BSS-simulated supercell; with a fixed environment, the supercell either shrunk in size and weakened over time, or grew upscale into a larger convective system. Quantitative comparisons examining distributions, areas, and volumes of vertical velocity and vorticity further confirm these differences. Overall, BSS provides a more realistic result, supporting the idea that a series of proximity soundings can sufficiently represent the effects of environmental variability, enhancing accuracy over fixed environments.
\end{abstract}

\section{Introduction and motivation}

Much of our current understanding of the fundamental dynamical processes governing severe convection is largely due to a number of idealized modeling studies using horizontally homogeneous, temporally fixed environments (e.g., Klemp et al. 1981; Rotunno and Klemp 1982; Rotunno and Klemp 1985; Droegemeier et al. 1993; Weisman and Rotunno 2000). The ability to cleanly diagnose cause and effect in this idealized setting is clearly beneficial, though is not without drawbacks. Notably, observed convective environments are largely

\footnotetext{
Corresponding author: Casey E. Davenport, casey.davenport@ uncc.edu
}

heterogeneous, varying (sometimes significantly) in both time and space (e.g., Brooks et al. 1996; Bunkers et al. 2006; Markowski and Richardson 2007; Letkewicz and Parker 2010; Ziegler et al. 2010; Parker 2014; Davenport and Parker 2015a; Wade et al. 2018). As a result, less is known about how these fundamental processes are modified or respond to changes in the local storm environment; such variations are known to influence storm structure, organization, maintenance, and severity (e.g., Bunkers et al. 2006; Richardson et al. 2007; French and Parker 2008; Ziegler et al. 2010; Davenport and Parker 2015b; Gropp and Davenport 2018).

In recent years, there have been a few different methods that have sought to bridge the gap between observed environmental variability and controlled, idealized 
simulations (e.g., Richardson et al. 2007; Parker 2008; Ziegler et al. 2010; see Letkewicz et al. 2013 for a review). Most recently, the base-state substitution technique (BSS; Letkewicz et al. 2013) was developed as a way to maintain horizontal homogeneity in the model while modifying the base-state environment in a controlled manner. Briefly, BSS entails the wholesale replacement of the horizontally homogeneous base state at a prescribed temporal interval while maintaining any storm-induced perturbations. If desired, the model user can independently modify the temperature, moisture, or wind profiles at a chosen interval without altering the structure of the perturbation fields (see Letkewicz et al. 2013 for complete details). In essence, BSS utilizes a storm-relative framework, wherein a storm is considered to experience a new environment at some rate as it moves through observed environmental variations; in other words, the background environment is updated via a series of proximity soundings that encapsulate the observed or imposed spatial and temporal environmental changes experienced by a storm. Notably, it is assumed that one base-state sounding can reasonably represent each new environment with sufficient accuracy; indeed, this is an assumption that underlies all idealized models with horizontally homogeneous environments.

BSS provides a significant amount of control over the environmental changes while also allowing for a clean determination of cause and effect. Indeed, it was designed to permit more realistic investigations of severe convection in an idealized setting, as explored by several recent studies (French and Parker 2014; Wipf and French 2014; Coffer and Parker 2015; Davenport and Parker 2015b; Crossett 2017). However, the extent of added realism afforded by implementing a series of proximity soundings, while suggested in recent studies using BSS, has yet to be assessed more deeply. For example, does this approach result in simulated storm structure and evolution fully consistent with observations? Is observed storm behavior reproduced in the model on a similar timeline? Or, can a single representative proximity sounding sufficiently reflect observed structure or behavior, even in a heterogeneous environment? Given the prevalence and continued utility of idealized modeling for controlled hypothesis testing, as well as the frequency of convection in environments containing storm-relative heterogeneities, it is of interest to conduct a detailed assessment comparing idealized simulations (with or without BSS) with observations of a storm in a heterogeneous environment.

The goal of the current study is to evaluate the ability of BSS to more realistically represent the structure and evolution of observed storms in comparison to idealized simulations with a fixed environment; this assessment will be completed using a combination of subjective and objective measures. The next section describes the data and methods of the study, including details of the observed case and associated simulations. Section 3 then reports the results of the simulations and provides analysis of BSS's performance. Finally, section 4 summarizes the key findings and identifies the primary conclusions of the study.

\section{Data and methods}

A thorough assessment of the faithfulness of model simulations to reflect reality requires an observational dataset of sufficient length and complexity to provide ample points of comparison. Ideally, dual-Doppler wind analyses would be available to examine similarities and differences in the three-dimensional flow field and other derived quantities to model output. Additionally, having these wind analyses available over an extended time period would be highly preferable to assess whether the model is able to capture any variability in storm behavior such as intensification or weakening. Correspondingly, given BSS's origins as a means to incorporate environmental variability in an idealized, horizontally homogeneous model, it is desirable to use a case where the storm-relative environment is evolving, and this variability is captured with a series of soundings. Here, a case of a supercell observed during the Deep Convective Clouds and Chemistry (DC3; Barth et al. 2015) field experiment on 29 May 2012 near Kingfisher, Oklahoma, provides an excellent dataset with these qualities, and has been successfully simulated in other studies using models where the background environment varies over both time and space (Yang et al. 2015; Bela et al. 2018). Dual-Doppler radar data was collected for over an hour, which importantly includes a period of rapid storm intensification. Additionally, three mobile soundings gathered that day demonstrate notable shifts in the temperature, moisture, and wind profiles of the inflow environment over a period of approximately four hours.

\section{a. Storm overview and observational data}

A detailed description of the evolution of the 29 May 2012 supercell is provided in DiGangi et al. (2016); thus, only a brief overview of the storm, environmental observations, and relevant data sources will be discussed. Key events in the initial development of the observed supercell, along with data collection periods, are summarized in Table 1 . In the afternoon on 29 May, an initial cumulus field matured into two convective cells oriented north-south near a dryline in western Oklahoma. The northern cell exhibited sustained deep convection and began producing lightning around 2120 UTC (all times 
are coordinated universal time), while lightning was first detected in the southern cell near 2134. The southern storm split shortly after 2200 , with the right mover identified as the Kingfisher supercell. During field operations, the Kingfisher storm intensified, as evidenced by rapidly increasing total flash rates and strengthening vertical velocity and vertical vorticity; the storm continued to intensify following the end of operations in response to merging with another supercell, resulting in hail up to $12 \mathrm{~cm}$ diameter and an EF-1 tornado. While the storm later dissipated, its remnants and other storms in the area continued to merge and eventually formed a mesoscale convective system (DiGangi et al. 2016).

Three storm-following mobile soundings (Ziegler 2013, cf. Table 1) captured the evolution of the environment from 2029 (preconvective, Fig. 1a), through 2255 (far-storm inflow, Fig. 1b), to 0020 (far-storm inflow, Fig. 1c). Over time, the environment became increasingly supportive of strong, rotating deep moist convection, particularly between 2255 and 0020 (Fig. 1). While average boundary layer conditions were relatively unchanged between 2029 and 2255, resulting in small changes in mixed-layer convective available potential energy (MLCAPE) and convective inhibition (MLCIN), notable moistening occurred both within the boundary layer and the lowest $3 \mathrm{~km}$ between the 2255 and 0020 soundings, prompting a significant increase in MLCAPE and slight decrease in MLCIN (Fig. 1; Table 2). The base of the elevated mixed layer near $800 \mathrm{hPa}$ also cooled over time, reducing the lid strength index (Graziano and Carlson 1987). Additionally, the low-level hodograph curved and lengthened, considerably increasing storm-relative helicity (SRH), though the magnitude of deep-layer shear remained essentially unchanged (Fig. 1). These environmental changes, particularly after 2255 , are consistent with the observed intensification trend of the Kingfisher storm after 2300 (DiGangi et al. 2016); such a connection is physically consistent with how a storm would be expected to evolve in the face of such conditions, and importantly implies that inclusion of environmental changes would be necessary to accurately portray storm evolution.

The environmental evolution captured by the three soundings described above encapsulates both spatial and temporal variability experienced by the Kingfisher supercell. To demonstrate the extent of spatial versus temporal heterogeneity present, low-level transects of potential temperature $(\theta)$, mixing ratio $\left(q_{v}\right)$, and winds sampled by the DC-8 aircraft (Chen and Olson 2018) are shown in Figs. 1e and 1f. The transects shown represent observations gathered between the first two soundings; the east-west leg was collected near $0.8 \mathrm{~km}$ above ground level (AGL) between 2110 and 2135, while the west-east
TABLE 1. Timings of observed cumuliform cloud formation, convection initiation $(\mathrm{CI})$, and storm/environment observations relative to the simulated 29-30 May 2012 Kingfisher, OK, supercell. The chosen time origin $T_{0}=2014$ UTC, which corresponds to initialization of the BSS simulation at $0 \mathrm{~h}$, qualitatively matches all observed and modeled events effectively in a least squares sense. The indicated soundings at 2029, 2255, and 0020 UTC and the radar analyses from 2251 UTC 29 May to 0000 UTC 30 May 2012 are described in the text.

\begin{tabular}{|c|c|c|}
\hline $\begin{array}{l}\text { Time } \\
\text { (UTC) }\end{array}$ & $\begin{array}{l}\text { Model time } \\
(\mathrm{h}, \mathrm{min})\end{array}$ & Event \\
\hline 2014 & $0 \mathrm{~h}$ & $\begin{array}{l}\text { Towering cumulus/cumulus congestus } \\
\text { east of dryline, initialize model }\end{array}$ \\
\hline 2029 & $0 \mathrm{~h} 15 \mathrm{~min}$ & 2029 sounding launch \\
\hline 2120 & $1 \mathrm{~h} 6 \mathrm{~min}$ & Observed CI of northern supercell \\
\hline 2134 & $1 \mathrm{~h} 20 \mathrm{~min}$ & $\begin{array}{l}\text { Observed CI of southern supercell, } \\
\text { modeled CI }\end{array}$ \\
\hline 2205 & $1 \mathrm{~h} 51 \mathrm{~min}$ & $\begin{array}{l}\text { Split of observed southern supercell to } \\
\text { form right-moving Kingfisher supercell }\end{array}$ \\
\hline 2251 & $2 \mathrm{~h} 37 \mathrm{~min}$ & First multiradar analysis \\
\hline 2255 & $2 \mathrm{~h} 41 \mathrm{~min}$ & 2255 sounding launch \\
\hline 0000 & $3 \mathrm{~h} 46 \mathrm{~min}$ & Last multiradar analysis \\
\hline 0020 & $4 \mathrm{~h} 6 \mathrm{~min}$ & 0020 sounding launch \\
\hline 0114 & $5 \mathrm{~h}$ & End model simulation \\
\hline
\end{tabular}

leg, initially near $2.1 \mathrm{~km}$ AGL and later descending to $0.9 \mathrm{~km}$ AGL, was collected between 2145 and 2200 . Thus, due to the distance covered within a relatively short amount of time by the DC-8, these in situ aircraft observations reveal horizontal heterogeneities with minimal evolution.

Although the DC- 8 data indicate a broad west-east decrease of $\theta$ extending from the primary dryline to a longitude between the 2029 and 2255 soundings, the DC- $8 \theta$ profile is roughly constant between the 2255 and 0020 sounding locations. There is also minimal horizontal variability of $q_{v}$ around the longitude interval of the sounding locations. Thus, the changes in the environment identified in the observed soundings were collectively influenced by both (limited) spatial gradients and evolution of the boundary layer. Indeed, $\sim 3-\mathrm{m}$ AGL observations obtained over a longer period of time by the NSSL mobile mesonet instrument rack (Ziegler 2015) attached to the rooftop of the mobile sounding vehicle suggests a stronger temporal component to the environmental surface layer evolution. Radiative surface layer stabilization likely dominated prior to sunset, particularly between the 2255 and 0020 sounding sites, as may be demonstrated by examining mobile mesonet-observed saturation point values trending downward approximately along a constant isohume on a skew $T-\log p$ diagram (not shown; e.g., Betts 1984, see Fig. 8 therein and related discussion). Note that the warm bias of $\theta$ from the mobile mesonet versus DC- 8 , combined with vapor mixing ratio values generally in good agreement between the platforms, is likely a result of a warmer surface layer whose Bowen 

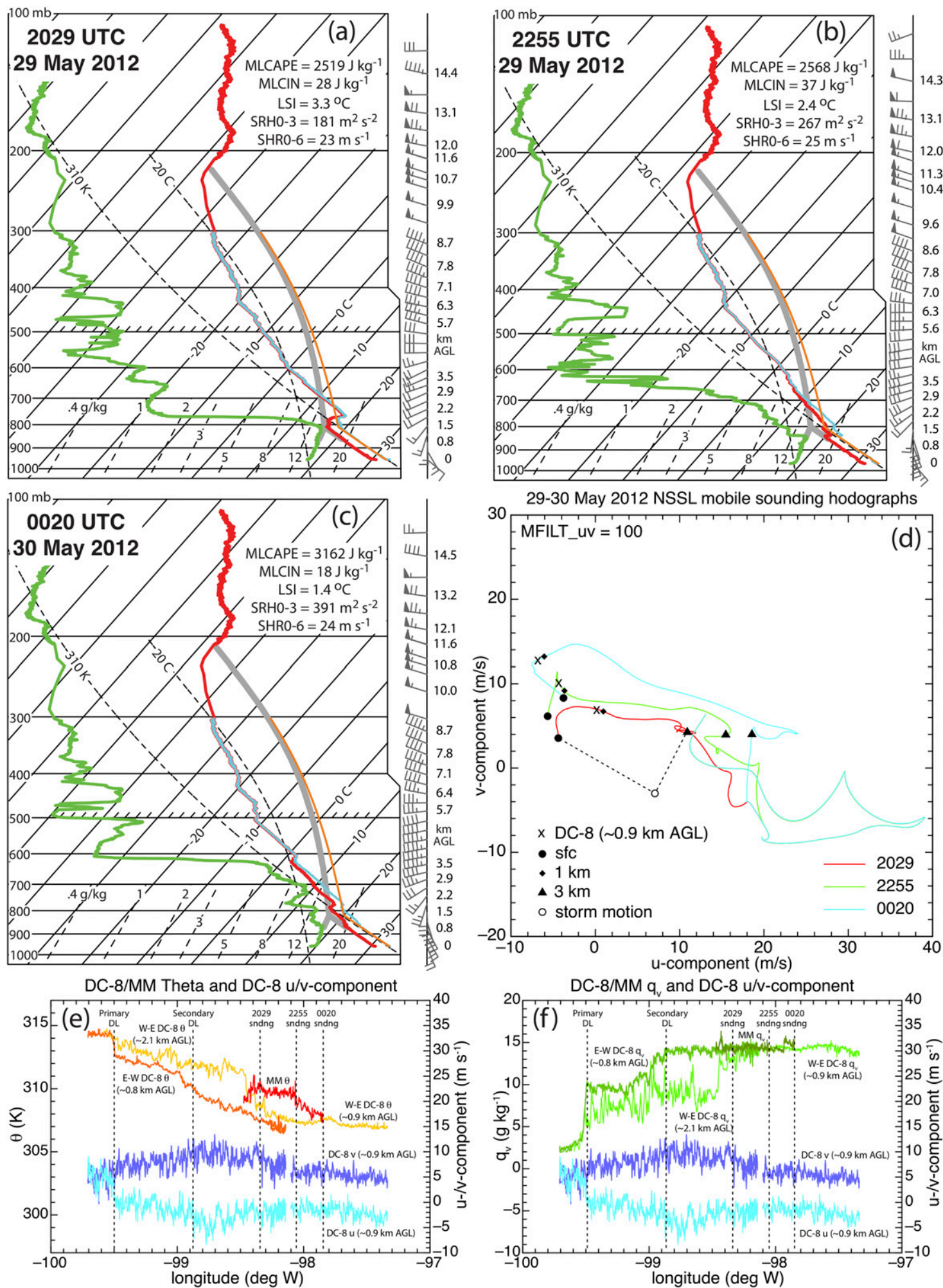

FIG. 1. Mobile storm-following environmental soundings launched at (a) 2029, (b) 2255, and (c) 0020 UTC 29-30 May 2012, along with associated thermodynamic and kinematic parameters, including mixed-layer convective available potential energy and convective inhibition (MLCAPE and MLCIN), lid strength index (LSI), 0-3 km storm-relative helicity (SRH0-3), and 0-6 km bulk vertical wind shear (SHR0-6). The orange and cyan curves (representing the lifted-parcel and environmental virtual temperature profiles) are shown to aid visualization of MLCAPE and MLCIN values. (d) The hodograph for each sounding with markers as labeled to indicate the location of 1 
TABLE 2. Selected sounding quantities that illustrate the observed heterogeneity of thermodynamic variables and lifting condensation level (LCL) in the boundary layer in north-central Oklahoma on 29-30 May 2012.

\begin{tabular}{cccccc}
\hline & \multicolumn{2}{c}{ Average boundary layer parcel quantities } & & \\
\cline { 2 - 6 } Sounding time (UTC) & $q_{v}\left(\mathrm{~g} \mathrm{~kg}^{-1}\right)$ & $\theta(\mathrm{K})$ & $\theta_{w}\left({ }^{\circ} \mathrm{C}\right)$ & LCL pressure (hPa) & LCL altitude (km AGL) \\
\hline 2029 & 14.3 & 307.1 & 23.5 & 810.4 & 1.4 \\
2255 & 14.2 & 307.8 & 23.6 & 800.9 & 1.6 \\
0020 & 15.4 & 307.5 & 24.3 & 819.8 & 1.4 \\
\hline
\end{tabular}

Ratio is dominated by sensible heat flux. A jump in vapor mixing ratio, potentially due to a shallow microfront, is evident between the 2255 and 0020 sounding locations, suggesting a spatial discontinuity not captured by the DC-8. Overall, these data suggest that temporal variations in the environment were rather more prominent than spatial heterogeneities relative to the moving storm, a scenario that BSS is likely able to better approximate (Letkewicz et al. 2013).

Mobile radar data were gathered by the Shared Mobile Atmospheric Research and Teaching Radars (SMART-Radars, SR1 and SR2; Biggerstaff et al. 2005; Biggerstaff 2014a; Biggerstaff 2014b) and the National Oceanic and Atmospheric Administration National Severe Storms Laboratory X-band polarimetric radar (NOXP; Burgess et al. 2010; Mansell 2014). Two to three radars collected time-synchronized volume scans every 3 min between 2251 and 0000 , a period in which rapid storm intensification was observed; the optimal radar pair (determined by the best viewing geometry at any gridpoint location) was used for dual-Doppler radar wind syntheses. The variational method described by Potvin et al. (2012) was applied, utilizing the 0020 inflow environmental sounding (Fig. 1c) as the background field for each synthesis and later smoothly blended toward the instorm winds using a low-pass spatial filter. The radar data were interpolated onto a $90 \mathrm{~km} \times 60 \mathrm{~km} \times 17.5 \mathrm{~km}$ Cartesian grid using natural neighbor interpolation (Ledoux and Gold 2005) and a horizontal and vertical grid spacing of $500 \mathrm{~m}$. The observed and derived quantities from these data will thus serve as the "ground truth" to which the idealized modeling results will be compared.

\section{b. Numerical model tests}

The idealized numerical model CM1 (Bryan and Fritsch 2002), release 19, was utilized for the modeling component of this study. The domain was $400 \mathrm{~km} \times$ $400 \mathrm{~km} \times 21 \mathrm{~km}$, with a horizontal grid spacing of $250 \mathrm{~m}$ and a stretched vertical grid $(100 \mathrm{~m}$ near the model surface to $500 \mathrm{~m}$ aloft; in total, 50 vertical levels). Convection was initiated using moist convergence (relative humidity initially set at $95 \%$ within the zone of convergence; Loftus et al. 2008) over the first $30 \mathrm{~min}$ of the simulation. A maximum divergence of $-5.5 \times 10^{-3} \mathrm{~s}^{-1}$ was applied over a $10 \mathrm{~km} \times 50 \mathrm{~km} \times 2.5 \mathrm{~km}$ box. This initiation technique was employed as a surrogate for the observed dryline forcing on 29 May 2012 (DiGangi et al. 2016). Model variables were integrated forward using a $1 \mathrm{~s}$ time step. A subgrid turbulence scheme based on the turbulent kinetic energy scheme of Deardorff (1980) was also used. Each simulation was run out for five hours, and the Coriolis term was not included. Simple open radiative lateral boundary conditions and a free-slip lower boundary condition were utilized, and no surface physics were included. Precipitation microphysics were governed by the National Severe Storms Laboratory (NSSL) double-moment variable graupel and hail density scheme (Mansell et al. 2010), with an initial cloud condensation nuclei $(\mathrm{CCN})$ concentration of $1.0 \times$ $10^{9} \mathrm{~m}^{-3}$ (Mansell and Ziegler 2013).

The observed soundings from the Kingfisher storm (Fig. 1) served as the base-state environment in the model simulations. Before incorporation into the model, quality control procedures were applied to the raw data. The sounding data time series (sampled every $1 \mathrm{~Hz}$, or approximately every $5 \mathrm{~m}$ vertically) were hole-filled via piecewise linear interpolation, and the horizontal winds in the surface layer $(\sim 10 \mathrm{~m}$ depth) were replaced by NSSL mobile mesonet surface wind observations to eliminate effects of launch from rest (e.g., Yurchak 2013). The hole-filled sounding data profiles were then low-pass filtered with a 15-pass application of a

\footnotetext{
$\longleftarrow$

and $3 \mathrm{~km}$ altitudes, the flight level of the DC- 8 observations, as well as the estimated storm motion used to compute SRH is shown. A lowpass filter with a period of $100 \mathrm{~s}$ was applied to lightly smooth the hodographs. (e),(f) Observations of potential temperature ( $\theta$; shown in red, orange, and yellow), mixing ratio ( $q_{v}$; shown in dark green, green, or light green), and $u$ and $v$ winds (shown in light or dark blue) from DC-8 and mobile mesonet (MM) transects. The direction and altitude of the DC- 8 flight legs are labeled, while the time periods of the east-west and west-east legs are 2110-2135 and 2145-2200, respectively. Note that the DC-8 leg times are between the 2029 and 2255 soundings. For reference, the longitude of the primary dryline, secondary dryline, and storm-following soundings are also labeled.
} 
two-sided triangular function with a half-width of $150 \mathrm{~m}$ and a reflection condition at the lower and upper boundaries of each sounding (e.g., Wade et al. 2018). This filter amplitude is sufficient to remove the roughly $15-20$ s pendulum oscillation period from the GPS horizontal winds, and also remove noise due to instrumentation sampling error, while otherwise preserving localized vertical shears that Wade et al. (2018) argued could potentially influence a storm's dynamical evolution.

As detailed in Table 1, convection initiation (CI) on 29 May 2012, indicated by sustained precipitating deep convection, strong reflectivity and high precipitation content, and vigorous lightning production, occurred in stages as different storms initiated and split from parent cells (additional details found in DiGangi et al. 2016). Although the definition of CI could generally depend on whether an emphasis is placed on formation processes in an individual supercell or alternatively in a line of supercells (Kain et al. 2013), the timings of $\mathrm{CI}$ in the individual storms in the present case were adequately close to one another to simply adopt the CI time of the (southernmost) Kingfisher storm. The Kingfisher supercell developed out of a split of the southern supercell that experienced $\mathrm{CI}$ at $2134,80 \mathrm{~min}$ after towering cumulus developed east of the dryline (Table 1). Thus, to replicate the environment that supported storm development, the initial model base state was approximated by linearly interpolating between the 2029 and 2255 soundings at 2134 . However, trial and error demonstrated that a slight moistening of the low-level environment (i.e., a 5\% increase in relative humidity in the lowest $4 \mathrm{~km}$ ) was needed to support long-lived convection. The remaining soundings were incorporated via BSS as described below, with the BSS profiles also being slightly moistened to retain the observed rate of change in moisture. Additional simulations not described herein demonstrated that the results were not sensitive to this choice.

The base-state environment was modified using an updated version of the base-state substitution method [as described in Davenport et al. (2017) and Fierro and Mansell (2017)]. The original BSS method involved stopping and restarting the model at a desired interval to separate the storm-induced perturbations from the base state and recombine them with a new base state [see Fig. 1 of Letkewicz et al. (2013)]. The current formulation ("continuous" BSS) applies tendencies to the base-state variables at every time step, which are computed according to the calculated environmental differences and the observed (or assigned) time between environments. Thus, the base state is updated every time step, before model variables are integrated forward.
To assess the extent of realism afforded by BSS in representing the structure, evolution, and behavior of observed storms in comparison to simulations with a fixed environment, a series of experiments were conducted. Two control simulations utilizing fixed base-state environments will be shown; one simulation containing the interpolated 2134 environment as the base state (hereafter CNTRL 2134), and another simulation with the 0020 observed environment as the base state (hereafter CNTRL 0020). A third simulation utilizing the 2255 sounding as the fixed base state was also conducted; however, storm evolution was quite similar to CNTRL 2134, and thus will not be shown. The BSS experiment (hereafter BSS) maintains the 2134 environment for the first $80 \mathrm{~min}$, a sufficient length of time to allow for CI and isolated supercell formation (e.g., Table 1). Following the 80 min mark, the base state is continually updated at every time step, gradually shifting the base state to the 2255 environment, then the 0020 environment. This modification occurs in "real model time", meaning that it takes $1 \mathrm{~h}$ and $21 \mathrm{~min}$ of simulated time to change the base state between the first two environments (2134 and 2255) and $1 \mathrm{~h}$ and $25 \mathrm{~min}$ to change the base state between the second two observed soundings (2255 and 0020). A distinction of the present study is thus that the simulated storms may be considered to be evolving in real time, which in turn enables a direct comparison of the radar-observed and simulated supercells. It should be noted, however, that only the CNTRL 2134 and BSS experiments shown herein provide a direct comparison of the same storm in a varying versus fixed base-state environment due to initiation in the same environment; the CNTRL 0020 simulation represents the formation and evolution of a storm that initiated in a different environment.

\section{c. Filtering of model data}

The model simulations contain finer horizontal and vertical grid spacings compared to the observed radar data. ${ }^{1}$ As a result, more details are resolved by the model than are apparent in the observations. Thus, to provide a more representative comparison between various model and observed fields, a two-dimensional nine-point elliptic filter (Haltiner and Williams 1980, p. 397) was applied horizontally to the model data. It

\footnotetext{
${ }^{1}$ Note that initial simulations of the Kingfisher supercell were run with $500 \mathrm{~m}$ horizontal grid spacing, producing results similar to those described herein in terms of simulated storm intensity and overall outcome (see Davenport et al. 2017). However, finer model resolution was chosen to better capture internal storm processes that are sensitive to environmental variability, thus influencing storm structure and evolution (e.g., Davenport and Parker 2015b).
} 
should be noted that the radar analysis (with $\Delta x=$ $0.5 \mathrm{~km}$ ) has a minimum resolvable (Nyquist) wavelength of $1 \mathrm{~km}$, whereas the model has a Nyquist wavelength of $0.5 \mathrm{~km}$. The modeled $u, v$, and $w$ components and vertical vorticity were each smoothed with 10 filter applications to pass more than $70 \%$ of wave amplitude at wavelengths longer than $6 \mathrm{~km}$ (i.e., $24 \Delta x$ in the model and $12 \Delta x$ in the radar analyses), more heavily damp increasingly shorter wavelengths, and eliminate the $1 \mathrm{~km}$ radar-Nyquist wavelength. Since the overall amplitude response of the radar analysis is also estimated to be very similar to the response of the latter elliptic ninepoint filter, the resulting low-pass filtering qualitatively better matched the passed model scales to the radarobserved storm-scale structures. As will become evident in the results, finescale modeled structures that could not satisfactorily be resolved by the radar analysis were a more significant issue in the CNTRL 0020 and BSS simulations. Consequently, both unfiltered and filtered model values will be shown as appropriate to demonstrate both the simulated storm dynamics and the influence of filtering on the comparisons.

\section{Results}

To address the study's goal, simulated storm structure and evolution will be compared to observations of the Kingfisher supercell using both subjective and objective measures. The focus will be on the period in which dualDoppler observations are available, between 2251 and 0000. Given that BSS is applied starting at $80 \mathrm{~min}$ into the simulation, and that both BSS and CNTRL 2134 were initiated with the same interpolated 2134 environment (aligned with the CI environment of the observed storm), the corresponding analysis period is between 157 and $226 \mathrm{~min}$. However, as will be described below, in the CNTRL 0020 simulation, more rapid supercell formation occurs ( $45 \mathrm{~min}$ into the simulation), resulting in a comparative analysis period between 45 and $114 \mathrm{~min}$. To reflect these similarities and differences in timing with the observations, comparisons will be shown relative to the corresponding simulated UTC time for CNTRL 2134 and BSS, while analysis times for CNTRL 0020 will be shown relative to simulated model time.

\section{a. Qualitative assessment}

To begin, we will examine the broad trends in the evolution of the observed Kingfisher storm as compared to the simulated evolution in CNTRL 2134, CNTRL 0020, and BSS. As shown in Fig. 2, the observed supercell traveled southeastward and clearly intensified over time during the analysis period, as indicated by a larger updraft area and overall increase in storm size. Notably, the midlevel updraft evolves from being elongated along the southwestern edge of the storm to becoming broader and more circular. At the same time, the storm expanded in size, particularly in the downshear and forward flank region. This intensification trend is in line with the observed shifts in the near-storm environment between 2255 and 0020 , particularly the increases in instability and SRH that are more supportive of strong, rotating convection (e.g., Coffer and Parker 2015).

In the experiments, a variety of simulated storm evolutions occurred. At 2251, the CNTRL 2134 simulation produced a supercell of fairly similar structure (although weaker simulated reflectivity) to the observed storm, with a broad area of downshear precipitation (Fig. 2). Additionally, a transient inflow notch and hook echo before 2310 associated with the western edge of the main updraft was present. Over time, however, the CNTRL 2134 supercell progressively weakened, with a shrinking updraft and significant decrease in storm size; the storm was nearly gone by 0000 .

The CNTRL 0020 simulation evolved in a markedly different manner. Soon after moist convergence was turned off, a supercell formed that was embedded at the southern end of an upscale-developing mesoscale convective system (MCS). This embedded supercell, while initially exhibiting features of a classic (CL) supercell, quickly evolved into a high precipitation (HP) supercell with a broadening, bow-shaped updraft on its southern flank (Fig. 2). However, this HP supercell phase did not last long, as the intensifying MCS and its attendant mesoscale cold pool predominated through the remainder of the simulation.

In contrast to both CNTRL 2134 and CNTRL 0020, BSS exhibited a simulated storm evolution more consistent with the observations than the other experiments. For example, stronger simulated reflectivities were exhibited further downshear. While the midlevel updraft did not evolve as markedly as the observations, as the supercell moved away from the initial zone of convergence, the increasingly supportive environment (i.e., larger instability and SRH) incorporated into the model contributed to maintenance and some apparent intensification of the storm on a similar time scale as the observations (Fig. 2). It should be noted that, while not shown here, additional simulations testing various model settings, including initiation techniques and changes in microphysics, largely confirm these various trends in all CNTRL and BSS experiments. Details of quantities like cold pool intensity or simulated reflectivity were impacted, but overall trends in storm evolution in each experiment remained the same.

Recall that the base-state environment in both CNTRL simulations remained fixed at either 2134 (representing 

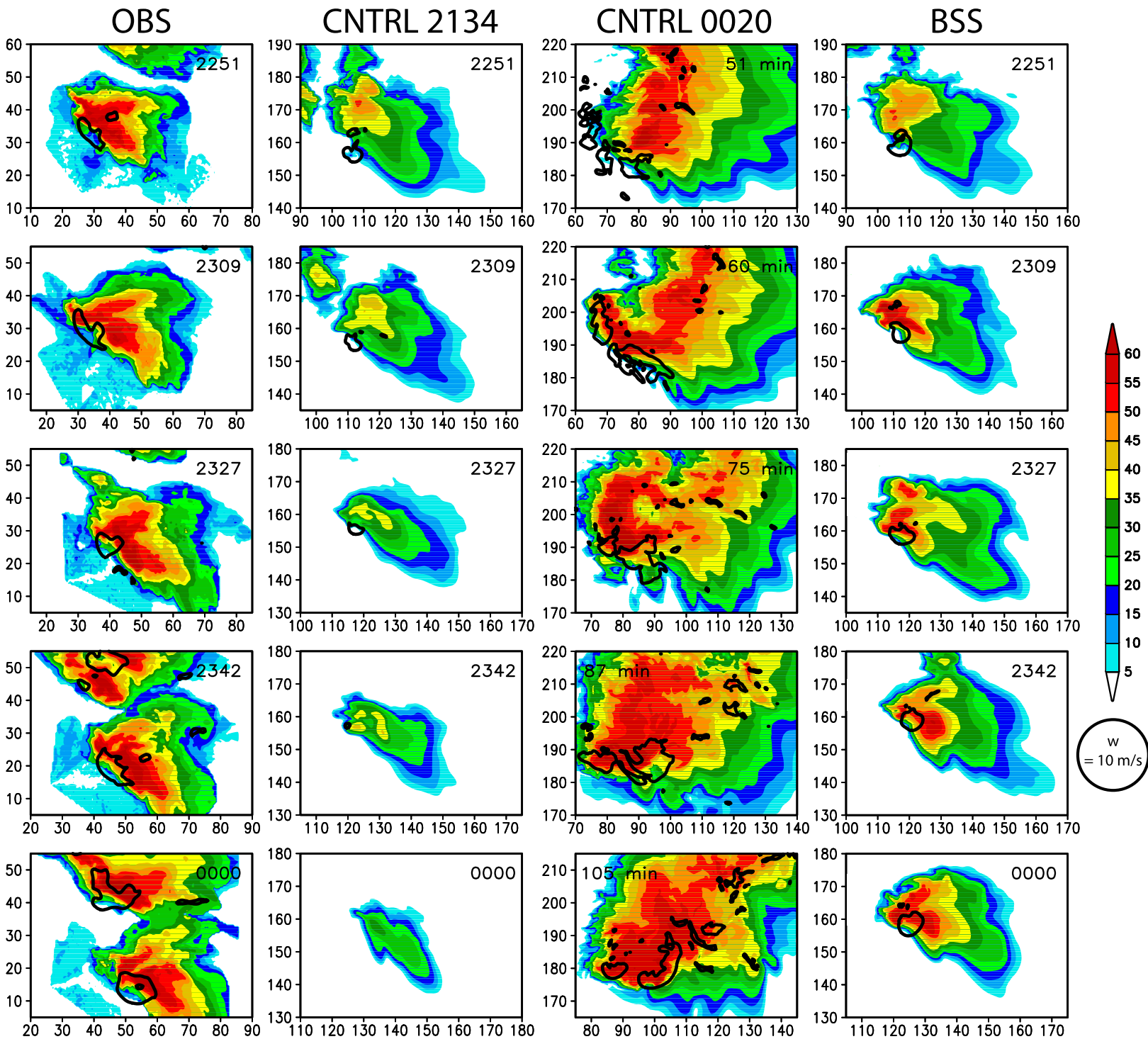

FIG. 2. Observed and simulated reflectivity (shaded) and vertical velocity at $5 \mathrm{~km}$ (contoured at $10 \mathrm{~m} \mathrm{~s}^{-1}$ ) of the Kingfisher supercell. The observations, CNTRL 2134, and BSS experiments are shown during the dual-Doppler deployment period, with observed/simulated times labeled in UTC. The CNTRL 0020 experiment is shown at select simulated times to demonstrate its rapid morphological evolution. The $x$ - and $y$-axis labels represent the distance (in $\mathrm{km}$ ) from the objective analysis or model domain origin.

an environment in between the preconvective neardryline sounding and the first near-storm sounding) or 0020 (representing the second near-storm sounding farther downstream of the dryline; Fig. 1). In the CNTRL 2134 simulation, the progressively weakening storm evolution indicates that the fixed environment was not in and of itself supportive of long-lived, rotating deep moist convection without the assistance of sustained mesoscale lift via the dryline (e.g., Ziegler and Rasmussen 1998). While not shown here, this outcome was also observed using the 2255 sounding as the fixed base state. The markedly different storm evolution present in the CNTRL 0020 simulation (CL to HP to MCS), though not unusual in the downstream dryline environment (Rasmussen and Straka 1998), was notably not observed in the Kingfisher supercell (i.e., refer to discussion in section 2a and details in DiGangi et al. 2016). A homogeneous-environment sensitivity test storm simulation by Ziegler et al. (2010) also resulted in a similar unobserved $\mathrm{CL}$ to $\mathrm{HP}$ to MCS evolution. It is well recognized by forecasters and modelers that upscale development via merging cold pools of widespread, persistent storms is fundamental to the MCS formation process (e.g., Ziegler 1999). 
The very moist midlevels of the 0020 sounding relative to the comparatively quite dry midlevels of both the 2134 and 2255 soundings are consistent with a greater likelihood of sustained deep, moist convection in the 0020 sounding (and possibly also greater likelihood of upscale development) due to a less diabatically cooled, negatively buoyant downdraft (Gilmore and Wicker 1998). The BSS simulation, leveraging a varying base-state environment, is the only experiment to produce a storm morphology that more realistically reproduces what was observed (Fig. 2).

The differing storm evolutions in the experiments are likely the result of other aspects of their background environments in addition to midlevel moisture as alluded to above. The 2134 environment, while possessing significant deep-layer shear supportive of supercells, was very warm and dry above the moist boundary layer with strong capping. Accordingly, dynamic entrainment of this warm and dry midlevel air would dilute the overall buoyancy of the main updraft (a process that is particularly harmful to sustained deep convection in low- and moderate-CAPE environments; James and Markowski 2010). While the near-inflow environment at 2255 developed a cooler, more moist midlevel layer, a significant cap was still present. Indeed, Graziano and Carlson (1987) noted that lid strength values above 2.0 (such as those present at 2029 and 2255) are associated with significantly decreased potential for deep convection, even with sufficient positive updraft inflow buoyancy. In contrast, the 0020 sounding possessed a very deep, rather cool and moist layer through approximately $3.5 \mathrm{~km}$, combined with weaker capping and larger CAPE. Accordingly, new secondary cells that were initiated by the preceding supercell outflow continued to develop in a minimally inhibited environment with large potential updraft buoyancies, further facilitating widespread convection that promoted rapid upscale growth to an MCS. As alluded to above, such an evolution is consistent with the tendency for storms in dryline environments to progress in this manner (Rasmussen and Straka 1998), as well as prior modeling work (e.g., the homogeneous simulation in Ziegler et al. 2010). It appears that the increasingly cooler, less stratified low- and midlevel temperature and moisture in the BSS experiment contributed to less dilution of the main updraft, thus further supporting convective intensity both thermodynamically via increasing CAPE and dynamically via increasing SRH due to enhanced low-level rotation and stretching of vertical vorticity (e.g., Coffer and Parker 2015).

To further illustrate the differing storm behaviors and trends, we will first discuss the progression of maximum vertical velocity profiles over time. In line with storm evolution shown in Fig. 2, the observed storm displayed generally increasingly intense updrafts, particularly in the mid- and upper levels $(\sim 5-10 \mathrm{~km}$ above ground level; all altitudes hereafter are with respect to the ground or model surface) after $\sim 2320$ (Fig. 3a), aligned with the increasing instability and weakening cap in the near-storm environment between 2255 and 0020 (Fig. 1), promoting stronger buoyancy accelerations. Accordingly, the storm steadily deepened within that time period, most evident between 2300 and 2345 (Fig. 3a). In CNTRL 2134, however, the strongest updrafts became significantly weaker throughout the depth of the storm, particularly after 2320 (Fig. 3b); the overall result is a shrinking and increasingly shallow storm. The CNTRL 0020 storm, on the other hand, rapidly intensified from the start of the analysis period through about $75 \mathrm{~min}$, indicated by a deepening of the updraft and unfiltered maximum updraft speeds nearly doubling (Fig. 3c), coinciding with the storm transition from a classic to high precipitation supercell (Fig. 2). The subsequent transition to the MCS phase resulted in a more quasi-steady updraft structure, with intermittent strengthening in the low levels (Fig. 3c). In BSS, unfiltered maximum vertical velocity magnitudes were broadly steady, though velocities in excess of $70 \mathrm{~m} \mathrm{~s}^{-1}$ (i.e., locally approaching up to at least $\sim 90 \%$ of parcel theory updraft magnitudes from the 2255 and 0020 soundings) appeared more frequently and over a greater depth in the storm after $\sim 2320$. Additionally, subtle strengthening in the midlevels (near 5-7 km) was evident as gradually descending velocity contours of 40 and $50 \mathrm{~m} \mathrm{~s}^{-1}$ (Fig. 3e).

While subtle, trends in maximum vertical velocity in BSS are broadly more consistent with the observations than the CNTRL simulations. Even so, it is worth noting that the vertical structure varied somewhat. In particular, the updrafts in all simulations tended to be stronger and deeper with a maximum located farther aloft compared to the observations; this is likely as a result of the simulations resolving features and processes not fully captured in the observations. Indeed, other studies have demonstrated a similar upward bias of the location of maximum vertical velocity in simulations compared to observations as a result of insufficient grid spacing and biases in microphysics parameterizations (e.g., Varble et al. 2014; Fan et al. 2017). Thus, application of the twodimensional filter helps to bring a greater degree of alignment between the simulations and the observations in terms of velocity structure and magnitude (Figs. 3d,f). Even so, the filtered velocities in CNTRL 0020 still exhibited a deeper and more intense updraft structure compared to the observations, likely a result of the larger environmental instability and enhanced low-level lifting from the MCS's cold pool (Fig. 3d). Filtered BSS velocities were more steady state than the unfiltered velocities, though the midlevels still exhibit gradually 


\section{Maximum Vertical Velocity}

a)

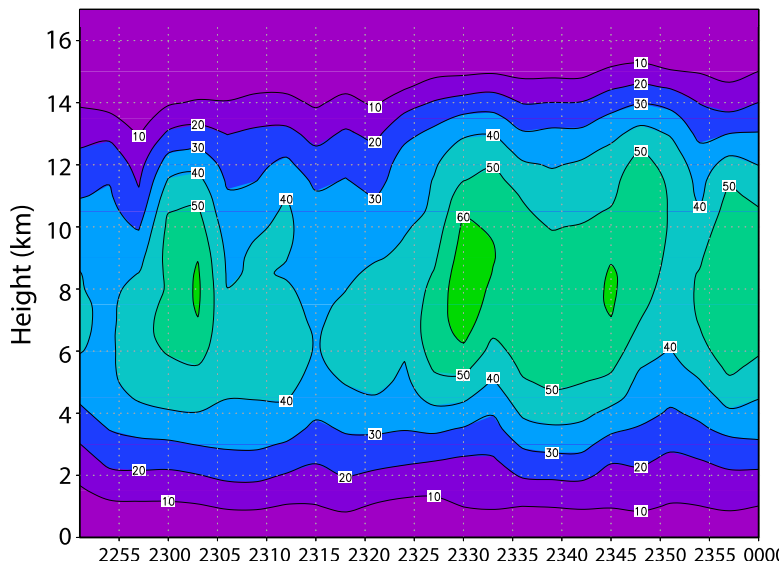

22552300230523102315232023252330233523402345235023550000 Time (UTC)
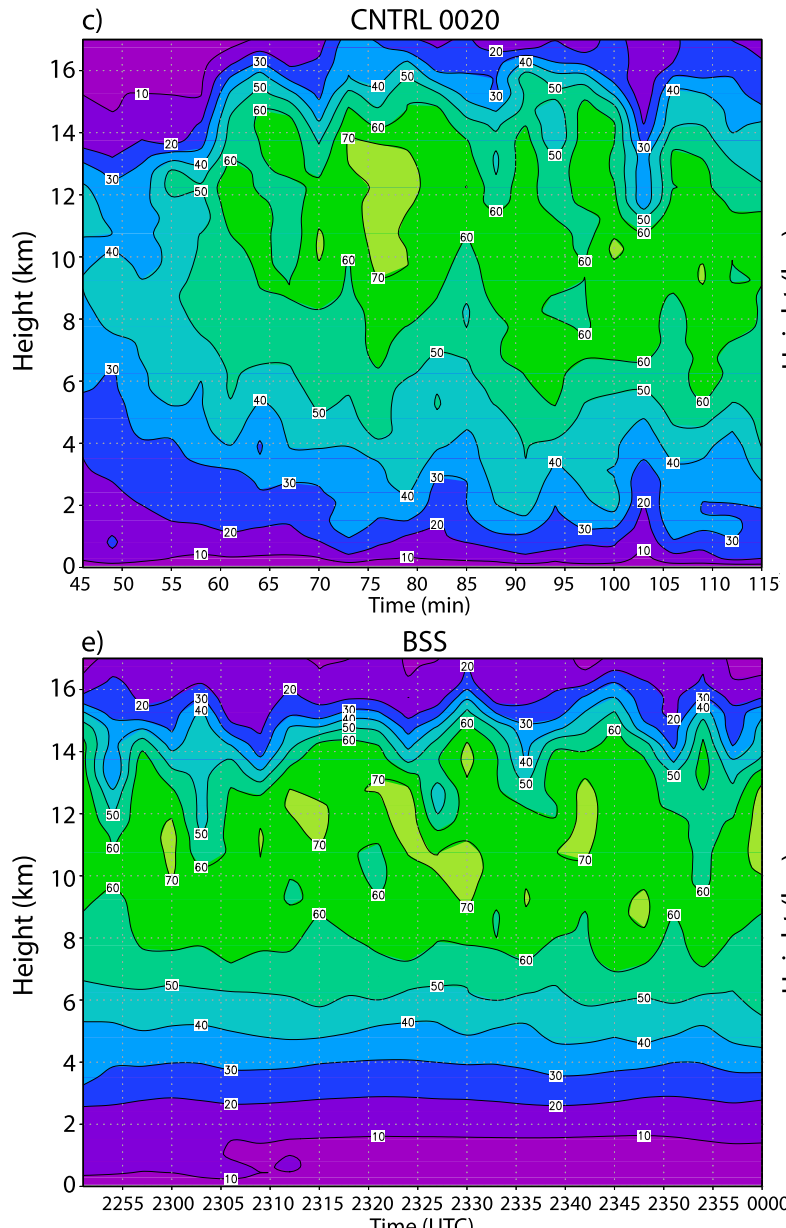

b)

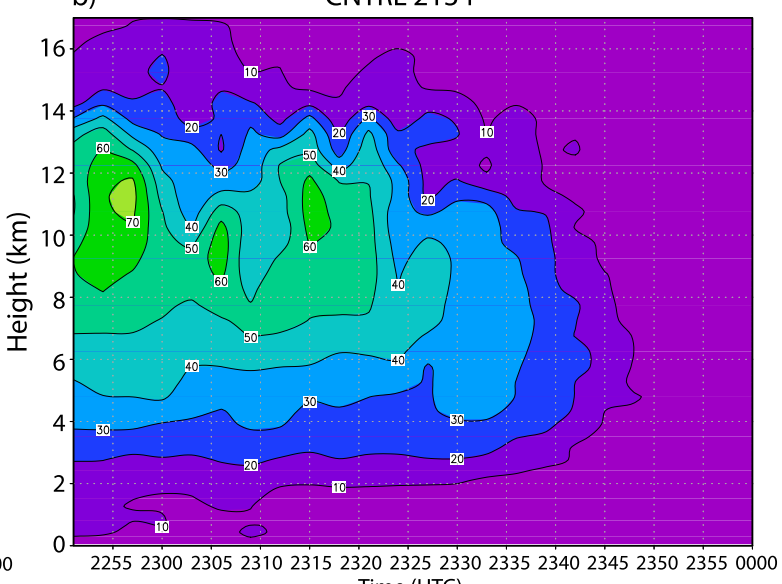

Time (UTC)

d)
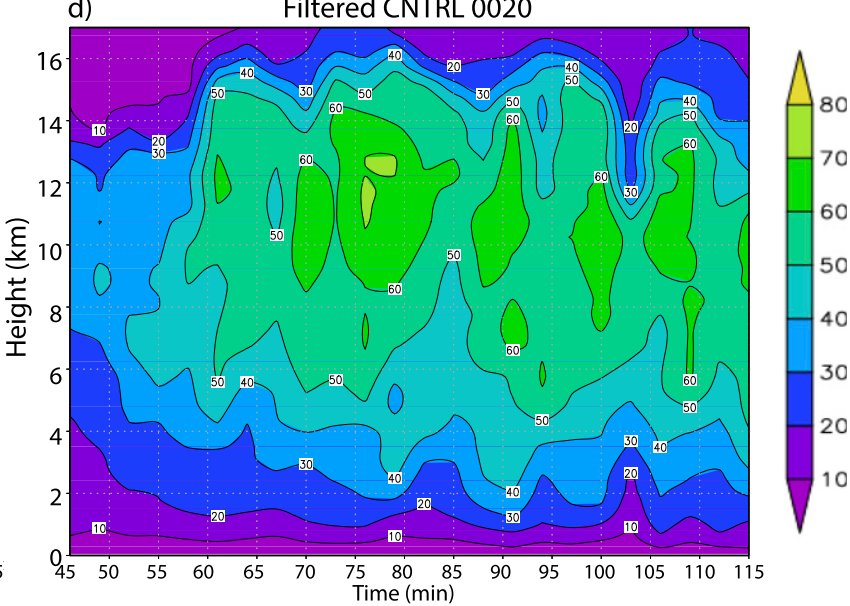

FIG. 3. Time-height plots of maximum vertical velocity (shaded and contoured every $10 \mathrm{~m} \mathrm{~s}^{-1}$ ) for the (a) observations (OBS), (b) control 2134 simulation (CNTRL 2134), (c) control 0020 simulation (CNTRL 0020), (d) filtered CNTRL 0020 simulation, (e) basestate substitution simulation (BSS), and (f) the filtered BSS simulation. The $x$ axis represents simulated or observed time, while the $y$ axis represents height in $\mathrm{km}$. 
intensifying maximum vertical velocities, evident as descending contours of 40 and $50 \mathrm{~m} \mathrm{~s}^{-1}$; the $10 \mathrm{~m} \mathrm{~s}^{-1}$ contour also descended slightly after 2350 (Fig. 3f).

The evolution of maximum vertical vorticity is similar to that of maximum vertical velocity. The radar observations indicate stronger rotation throughout the storm over time, most significantly after 2335 between 6 and $12 \mathrm{~km}$, though vorticity in the lowest $2 \mathrm{~km}$ also strengthens, indicating the development of a low-level mesocyclone after 2325 (Fig. 4a). The overall increasing trend of lowlevel rotation is consistent with stronger low-level winds and SRH producing enhanced vertical vorticity and stretching of vertical vorticity (e.g., Coffer and Parker 2015). In the simulations, the magnitude of vertical vorticity is again much greater than the observations, with varying trends and features of note. For example, a transient simulated low-level mesocyclone is evident in CNTRL 2134 and BSS before 2310 (Figs. 4b,e), associated with the previously noted inflow notch and hook echo feature (Fig. 2). During the supercell phase of CNTRL 0020, a descending mesocyclone is also present (Figs. 4c,d). However, in CNTRL 2134, as updrafts weakened and provide less support for stretching, maximum vertical vorticity rapidly decreased in magnitude over time (Fig. 4b). In contrast, as updrafts intensified throughout the CNTRL 0020 storm, vertical vorticity also strengthened (Figs. 4c,d). Similarly, the BSS supercell exhibited more intense mid- and upperlevel vertical vorticities in conjunction with stronger updrafts in those regions (Figs. 4e,f; cf. Figs. 3e,f). Notably, filtered vertical vorticity in BSS exhibits more consistent midlevel values above $0.03 \mathrm{~s}^{-1}$ after 2330 , as well as some strengthening below $4 \mathrm{~km}$, timing similar to the observations (Fig. 4d).

The evolution of maximum vertical velocity or vertical vorticity is informative of storm behavior, but it is not necessarily fully representative. Consequently, we wished to examine the trends in the distributions of vertical velocity and vertical vorticity, accomplished through contoured frequency by altitude diagrams (CFADs; Yuter and Houze 1995). Bins of $2 \mathrm{~m} \mathrm{~s}^{-1}$ and $0.002 \mathrm{~s}^{-1}$ for vertical velocity and vertical vorticity, respectively, were used. The distributions were created at each vertical level in both the observations and the simulations using a $35 \mathrm{~km} \times 35 \mathrm{~km}$ box surrounding the updraft; for CNTRL 0020, this box first encompassed the primary supercell updraft, and later the main updraft at the leading edge of the MCS. This size was chosen to focus on the properties of the updraft itself without being influenced by any nearby convection (e.g., evident toward the end of the observed analysis period in Fig. 2).

The distribution of vertical velocities in the observed Kingfisher supercell underwent some notable changes during the analysis period, most significantly in the 99th percentile of the distribution that represented the core of the storm's updraft. Over time, the core updraft significantly strengthened, particularly in the mid- and upper levels ( 5-10 km; Fig. 5), in line with the maximum values displayed in Fig. 3a. For example, at 2251, the midlevel updraft (near $4-8 \mathrm{~km}$ ) was around $20 \mathrm{~m} \mathrm{~s}^{-1}$. In contrast, the updraft at $8 \mathrm{~km}$ had doubled in intensity to $40 \mathrm{~m} \mathrm{~s}^{-1}$ by 0000 , with the largest increase between 2339 and 0000 , corresponding to the strongly increasing environmental instability and SRH (Fig. 1). Furthermore, the frequency of velocities occurring at or above the 99th percentile also increased over time. Other portions of the vertical velocity distribution were also modified. For example, the 95th percentile, representing the broader storm updraft, steadily strengthened over time in the midlevels, increasing from $\sim 10 \mathrm{~m} \mathrm{~s}^{-1}$ at 2251 to $\sim 20 \mathrm{~m} \mathrm{~s}^{-1}$ by 0000 (Fig. 5). Less significant shifts were present in the storm's downdraft. For example, the 1st percentile, representing the core of the downdraft, exhibited slight strengthening followed by weakening in the upper levels $(\sim 10-12 \mathrm{~km})$, and the reverse pattern at low to midlevels $(\sim 2-4 \mathrm{~km})$, with relatively small changes in magnitude.

At the start of the analysis period, the overall shape of the simulated vertical velocity distributions differ from the observed distribution. In CNTRL 2134 and BSS, the upper-level simulated velocities span a wider range of values than the observed due to the deeper nature of the simulated convection (Fig. 5). Notably, the core of the updraft (i.e., the 99th percentile) in BSS is already stronger than the updraft core in CNTRL 2134 at 2251, presumably due to the incorporated shifts in the base-state environment that the storm has experienced. The initial CNTRL 0020 distribution is narrower than the other simulations, though its broad updraft (i.e., the 95th percentile) is more intense than either CNTRL 2134 or BSS.

Over time, as the environment in BSS evolves (becoming increasingly favorable for strong, rotating convection; Fig. 1), yet remains constant in the CNTRL simulations, the vertical velocity CFADs of the simulations significantly diverge. Consistent with the overall weakening of the CNTRL 2134 supercell (Fig. 2), its vertical velocity distribution narrows considerably over time. In contrast, the supercell to MCS transition in CNTRL 0020 produces a rapid widening and intensification of the vertical velocity distribution; the core updraft doubles in intensity between 51 and $66 \mathrm{~min}$, followed by strengthening of the downdraft as the MCS matures toward the end of the analysis period (Fig. 5). The BSS distribution, meanwhile, evolves in more subtle ways. The peak core updraft magnitude around $8 \mathrm{~km}$ slightly increased over time through 2339 , 


\section{Maximum Vertical Vorticity}

a)

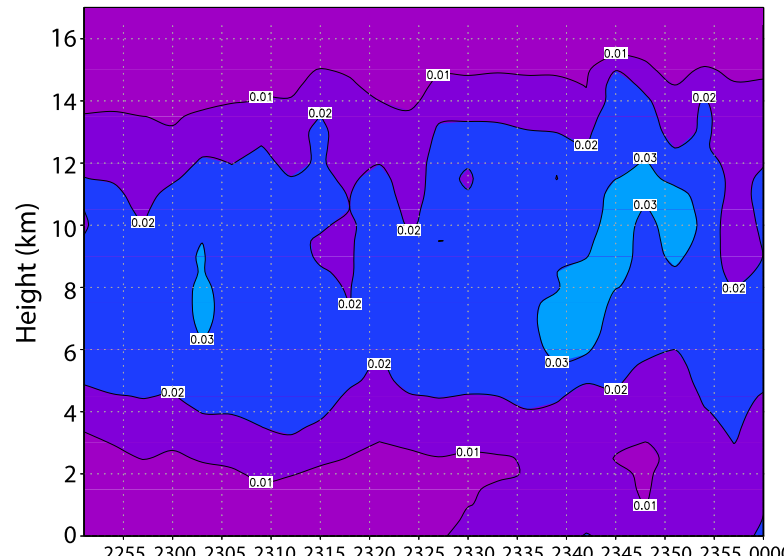

22552300230523102315232023252330233523402345235023550000 Time (UTC)
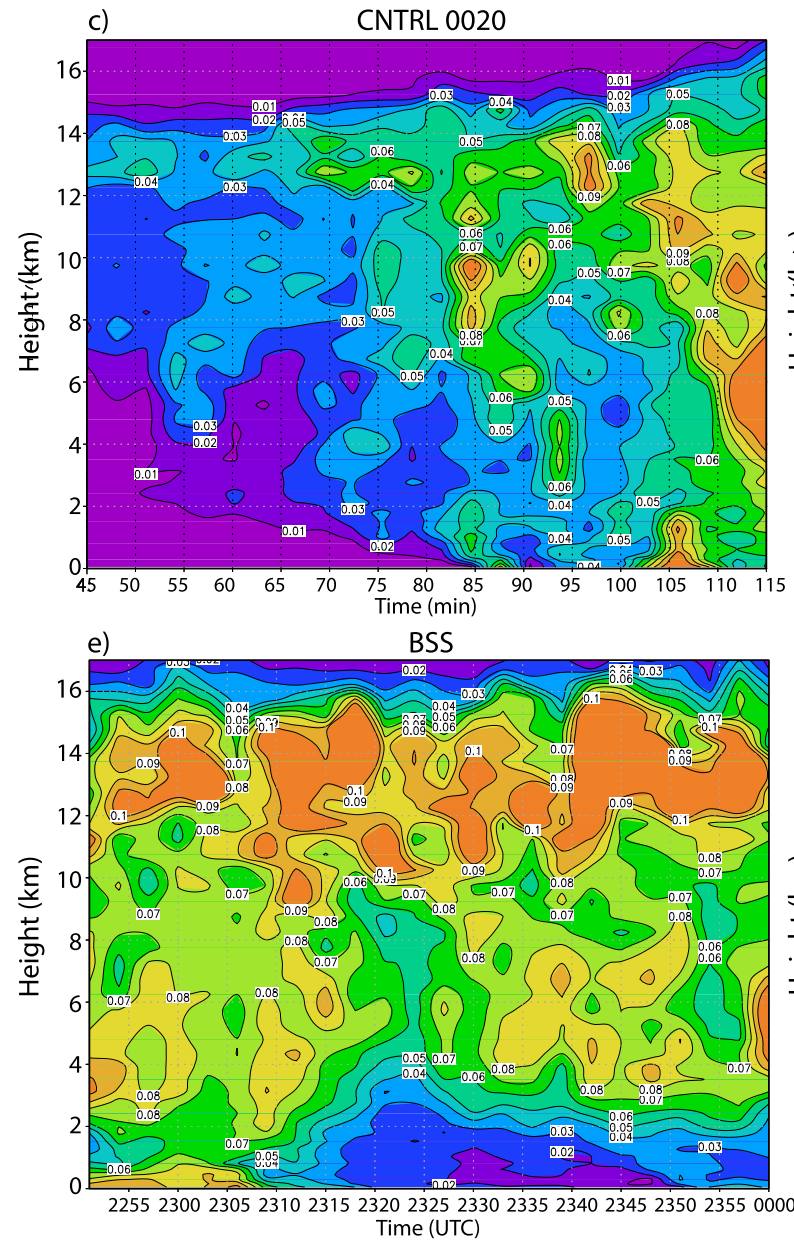

b)

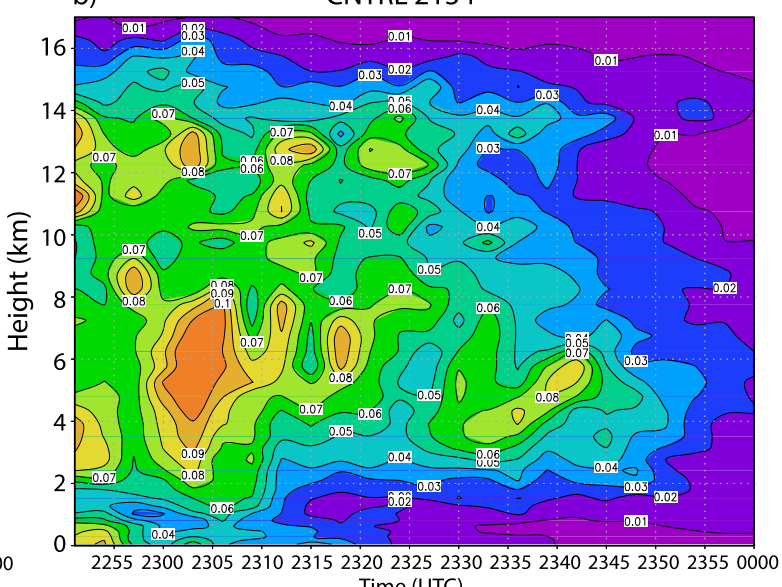

Time (UTC)
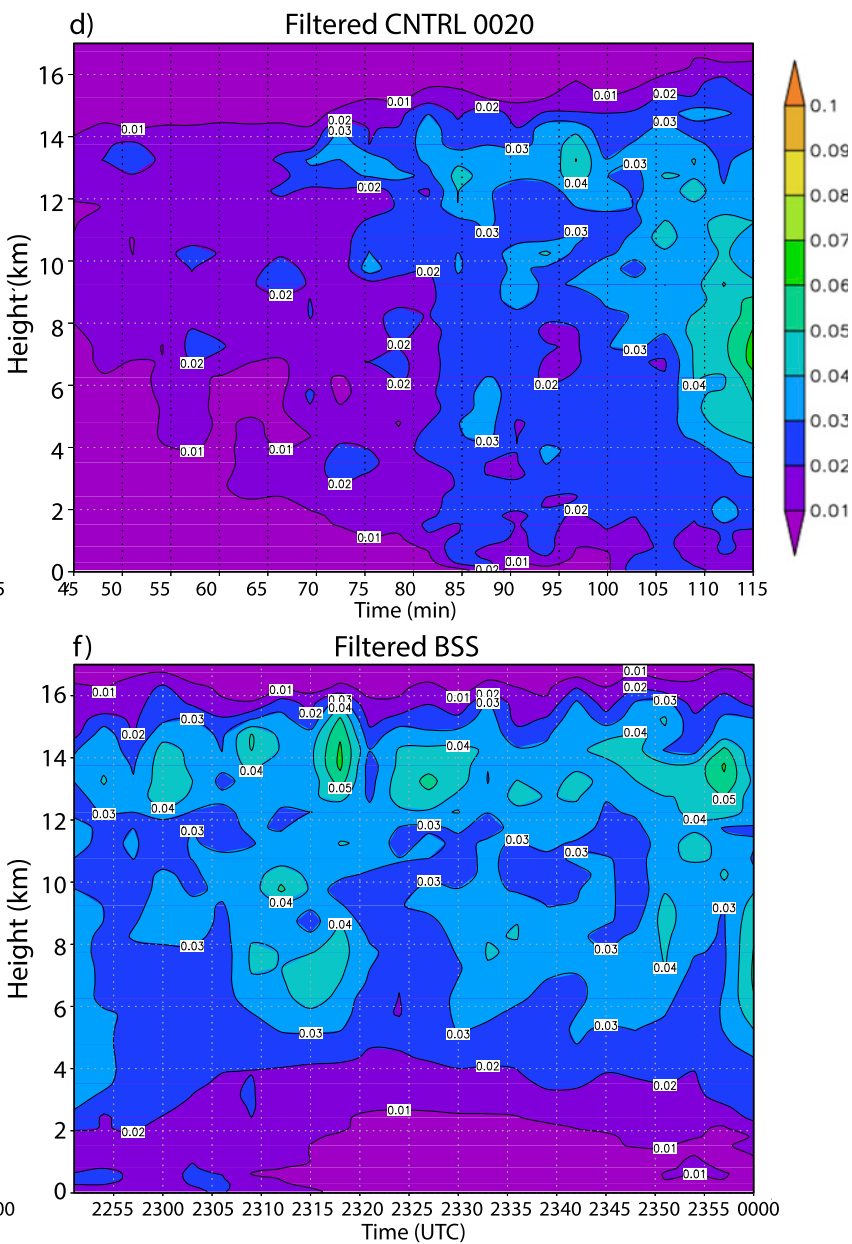

FIG. 4. As in Fig. 3, but for maximum vertical vorticity, shaded and contoured every $0.01 \mathrm{~s}^{-1}$.

though largely remained near $35-40 \mathrm{~m} \mathrm{~s}^{-1}$. Even so, those and higher velocity values tended to encompass a larger fraction of the analysis domain, indicated by a subtle increase in warmer colors at and above the 99th percentile, particularly in the mid- and upper levels; a similar evolution can also be observed around the 95th percentile (Fig. 5). In other words, the updraft volumetrically increases over time, a trend that will be quantified in 


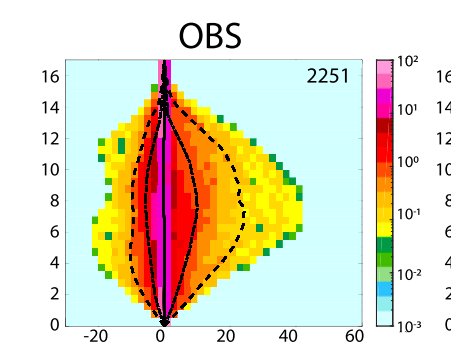

CNTRL 2134

Filtered CNTRL 0020

Filtered BSS
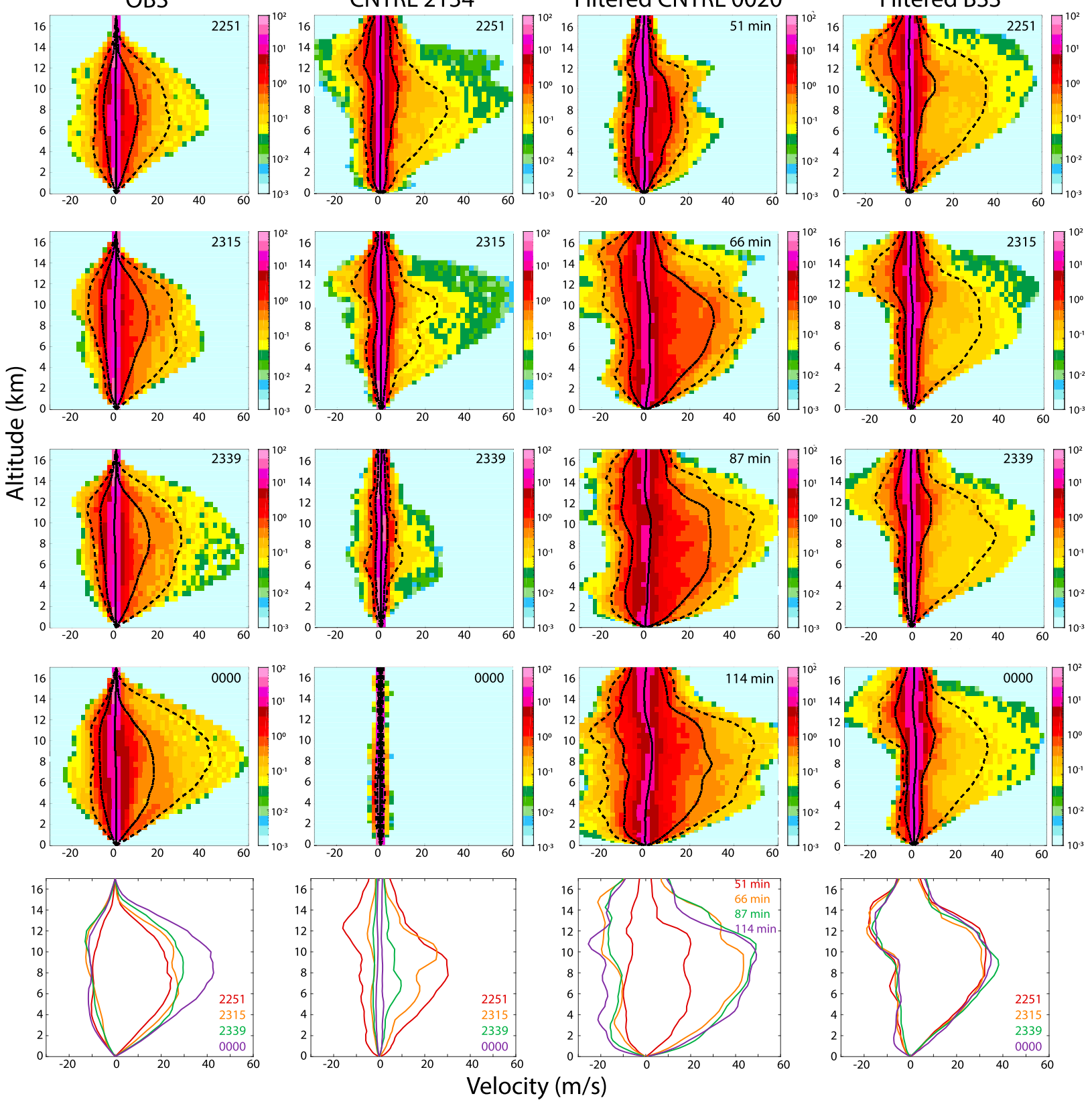

FIG. 5. CFADs of vertical velocity (binned every $2 \mathrm{~m} \mathrm{~s}^{-1}$ ) at select times for (from left to right) the observations (OBS), CNTRL 2134, filtered CNTRL 0020, and filtered BSS. Frequency of occurrence (i.e., the fraction of grid points at every vertical level within a given velocity bin) is shaded using a logarithmic scale. The contours represent the 1st, 5th, 50th, 95th, and 99th percentiles of the distribution. The 1st and 99th percentiles are dashed, the 5th and 95th percentiles are dot-dashed, and the 50th percentile is a solid contour. The bottom row shows the evolution of the 1st and 99th percentiles of the distribution.

the next subsection. In BSS, the core downdraft in the upper levels slightly weakens over time, while the mid- and low-level core downdraft remains steady state, except at 0000 when it increases slightly in magnitude. Despite differences in some of the distribution details, the BSS supercell is largely much more representative of the observations than the CNTRL experiments.
CFADs of vertical vorticity for both the observations and simulations generally evolve somewhat more subtly than the vertical velocity CFADs, yet distinct trends are still present. In the observed supercell, the most extreme upper end of the distribution (99th percentile and above) in the midlevels intensifies slightly in the latter half of the analysis period and appears to increase in 
area (i.e., higher vorticity values occurring at a higher frequency); this trend is also true for the lower end of the distribution (1st percentile and below; Fig. 6). It is also evident that low-level rotation (approximately within the lowest $2 \mathrm{~km}$ ) intensifies slightly and comprises more of the analysis domain, particularly toward 0000. In CNTRL 2134, there is a significant narrowing of the distribution of vertical vorticity throughout the depth of the storm, consistent with overall storm weakening (e.g., Figs. 2, 5). Note that while the magnitude of vertical vorticity in CNTRL 2134 becomes more comparable to the observations (cf. Fig. 4), the evolution is clearly different. The reverse trend is present in CNTRL 0020, where the vertical vorticity distribution rapidly widens throughout the depth of the storm, most significantly following the transition to an MCS. In BSS, the trend is more subtle, where the shape of the distribution is fairly steady state, yet broadly encompasses a larger fraction of the domain over time, particularly in the upper levels (near 10-14km; Fig. 6). Notably, however, none of the simulations, including BSS, are able to accurately reflect the shape of the observed distribution, particularly the hourglass shape that develops in the lowest $5 \mathrm{~km}$. This suggests that, while BSS better represents the overall trends present in the vertical vorticity distribution, all of the idealized simulations are still limited in their ability to realistically reproduce the evolution of low-level vorticity, specifically the intensification and broadening present in the lowest $2 \mathrm{~km}$ toward the end of the analysis period.

In summary, visual inspection of the overall trends in the CNTRL and BSS simulations in terms of reflectivity, vertical velocity, and vertical vorticity are quite different, with BSS clearly displaying attributes more similar to the observed Kingfisher supercell. To supplement and further quantify these qualitative trends, additional quantitative measures of comparison are described next.

\section{b. Quantitative assessment}

The first quantitative measure that will be presented is updraft area; here, we examine the size of the broad updraft (defined as vertical velocities in excess of $5 \mathrm{~m} \mathrm{~s}^{-1}$ ), as well as the updraft core (defined as vertical velocities in excess of $30 \mathrm{~m} \mathrm{~s}^{-1}$ ), throughout the depth of the storm. These thresholds roughly correspond to the intensity of the 95th and 99th percentiles of midlevel vertical velocity at the start of the analysis period (Fig. 5). ${ }^{2}$ Consistent with the evolution shown in Fig. 2,

\footnotetext{
${ }^{2}$ Given the variation in intensity among the observed and simulated storms, these values were chosen to be the most representative thresholds for examination. Additional thresholds were examined, but the overarching results were unchanged.
}

the broad updraft within the observed supercell grew significantly in size over time, particularly in the midlevels. For example, at $7 \mathrm{~km}$, the updraft more than doubled in size from approximately 125 to $260 \mathrm{~km}^{2}$ between 2251 and 0000, with the largest jump near the very end of the analysis period (Fig. 7a). The broad updraft in CNTRL 2134 started the analysis period as nearly the same size as the observations $\left(\sim 120 \mathrm{~km}^{2}\right.$ at $\left.10 \mathrm{~km}\right)$, but shrunk steadily over time, resulting in a nearly nonexistent updraft at 0000 (Fig. 7b). The CNTRL 0020 storm exhibited significant growth in the size of the broad updraft, particularly in the first half of the analysis period during the transition from supercell to MCS and in the low levels as the cold pool developed and matured (Fig. 7c). While this trend of substantial growth in the size of the updraft is consistent with the observations, the actual size throughout the depth of the storm is much larger than was observed. Additionally, the broad updraft ceased its rapid expansion and even shrunk in places in the latter half of the analysis period, whereas the observations demonstrated the most growth during this timeframe (Figs. 7a,c). The broad updraft in the BSS supercell evolved in a more subtle manner than the other simulations, though there were some similarities to the observations. During the first half of the analysis period, the broad updraft was fairly steady state in size, but appreciable increases in size were evident at 2354 and 0000 between 8 and $12 \mathrm{~km}$ (Fig. 7d). Even while the overall trend in updraft area is not as unambiguous as the observations, the BSS provides a comparatively more realistic representation than the fixed-sounding simulations.

Examination of the evolution of the vertical profile of the core updraft area also reveals notable trends. In the observations, the overall trend in the size of the core updraft is not one of continuous growth like the broad updraft; significant increases in size occur early on between 2251 and 2300, followed by reduction through 2318 , and finally a more sustained expansion after 2318 , most notably near 0000 . Between the start and end of the analysis period, the most substantial growth is visible near $8 \mathrm{~km}$, where the core updraft quadruples in size from $6 \mathrm{~km}^{2}$ at 2251 to $25 \mathrm{~km}^{2}$ at 0000 (Fig. 8a). Meanwhile, the core updraft in CNTRL 2134 starts out larger than the observations, with a peak value of $12 \mathrm{~km}^{2}$ at $8 \mathrm{~km}$, but consistently and rapidly shrinks over time, particularly after 2309 (Fig. 8b). The CNTRL 0020 storm begins with a nearly nonexistent core updraft, however this quickly changes with a significant expansion in size throughout the depth of the storm. Core updraft size peaks near $99 \mathrm{~min}$, followed by a notable shrinking through the end of the analysis period, potentially a result of low-level lifting beginning to 


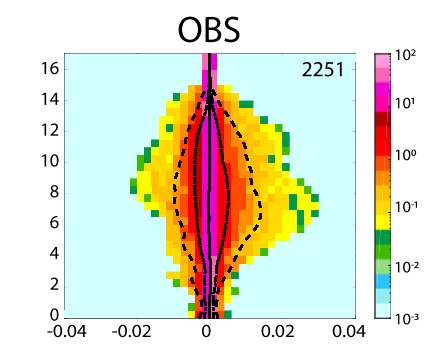

CNTRL 2134

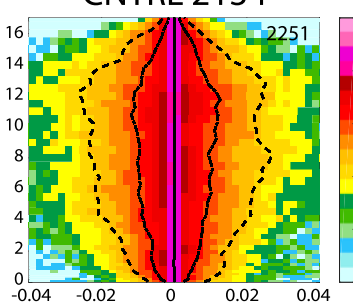

Filtered CNTRL 0020
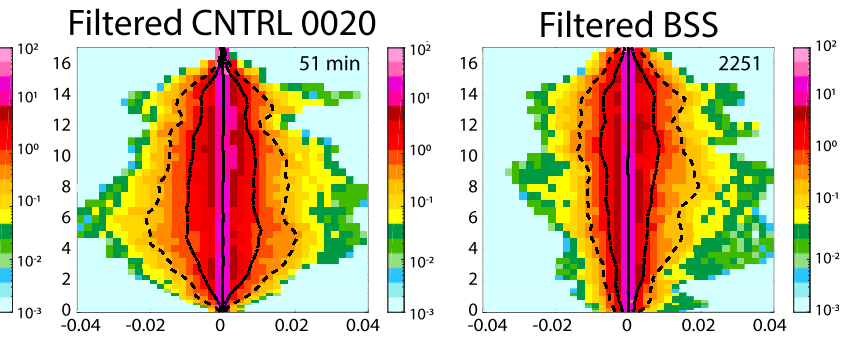
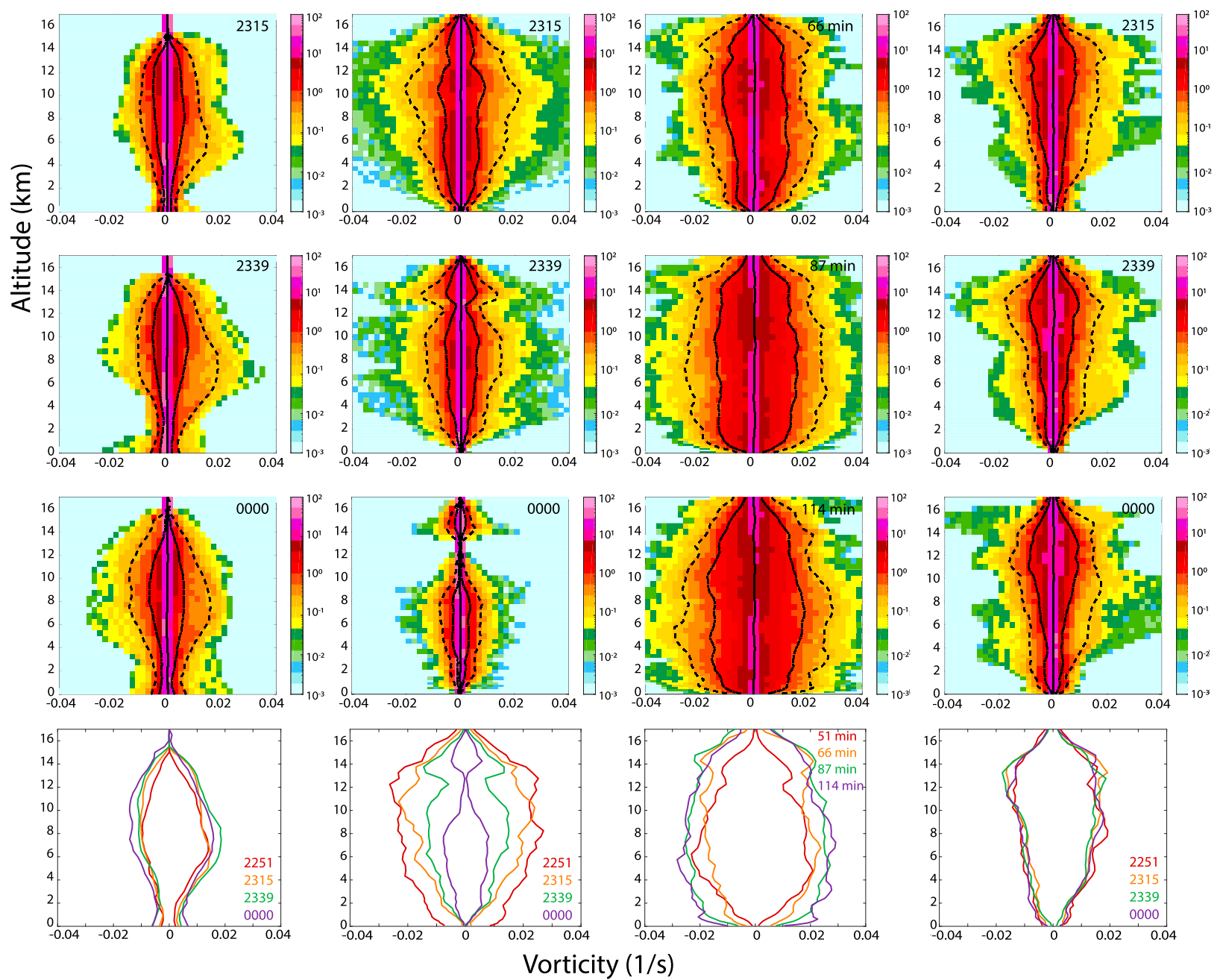

FIG. 6. As in Fig. 5, but for CFADs of vertical vorticity (binned every $0.002 \mathrm{~s}^{-1}$ ).

dominate as the MCS matures (Fig. 8d; cf. Fig. 2). In BSS, fluctuations in the size of the core updraft occur over time, similar to the observations. For example, some expansion is evident near $8-10 \mathrm{~km}$ through 2309 , followed by a rapid decrease in size through 2318 , then steadier growth through 2345. Further fluctuations occur between 2345 and 0000 , with the end of the analysis period demonstrating a trend toward a larger core updraft (Fig. 8d). While there are also some notable dissimilarities in trends in the observed and BSS core updraft (such as a lack of BSS core updraft deepening over time), BSS nevertheless is a more accurate reflection of the observed evolution as compared to the CNTRL experiments.

The trends in observed vertical vorticity, with a focus on areas with values of at least $0.01 \mathrm{~s}^{-1}$ (i.e., delineating a mesocyclone), are generally more subtle and variable than the updraft area trends. A fairly consistent tilted-stretched midlevel mesocyclone is evident, with the exception of an increase in size early in the analysis period (Fig. 9a). The upper levels (between 10 


\section{Updraft area $>5 \mathrm{~m} / \mathrm{s}$}

a)

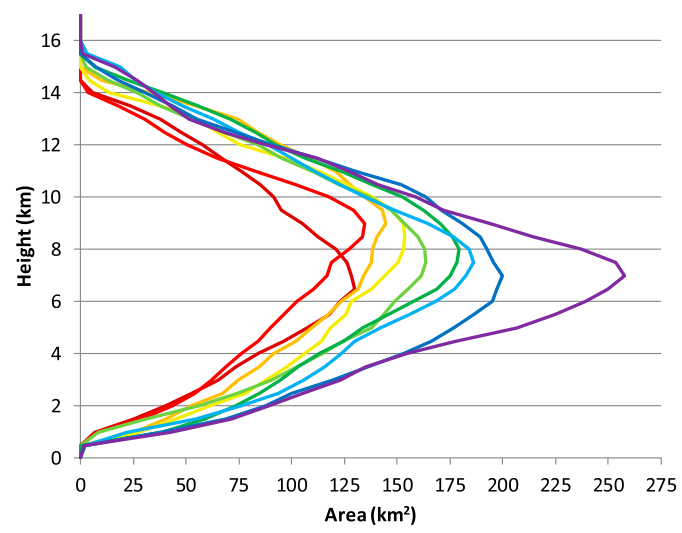

c)

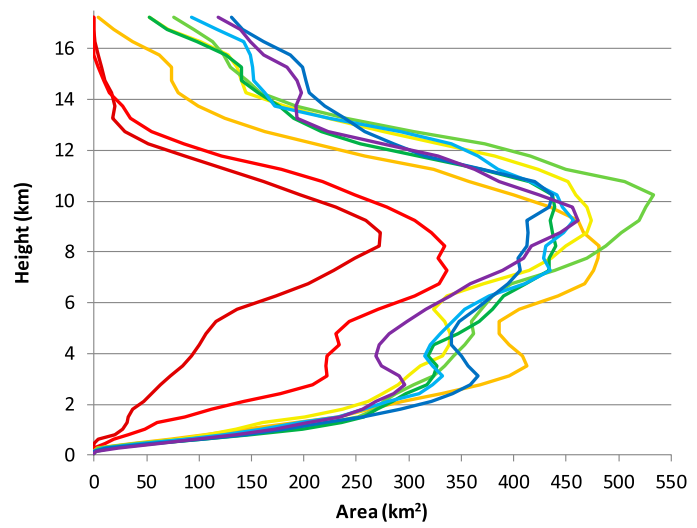

b)

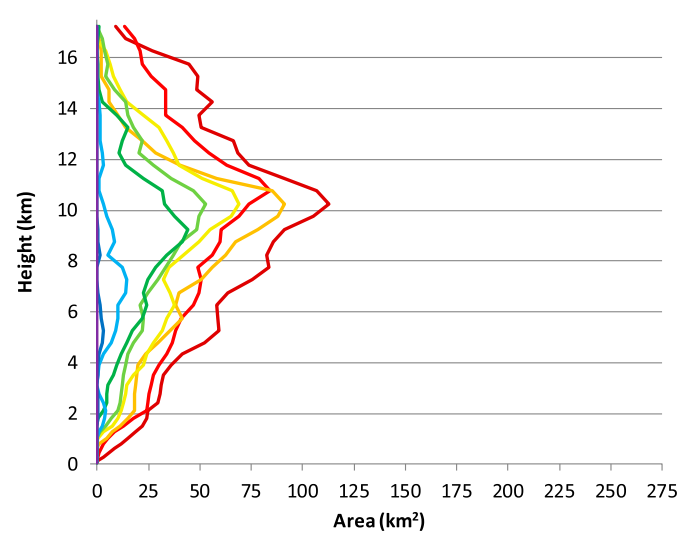

d)

Filtered BSS

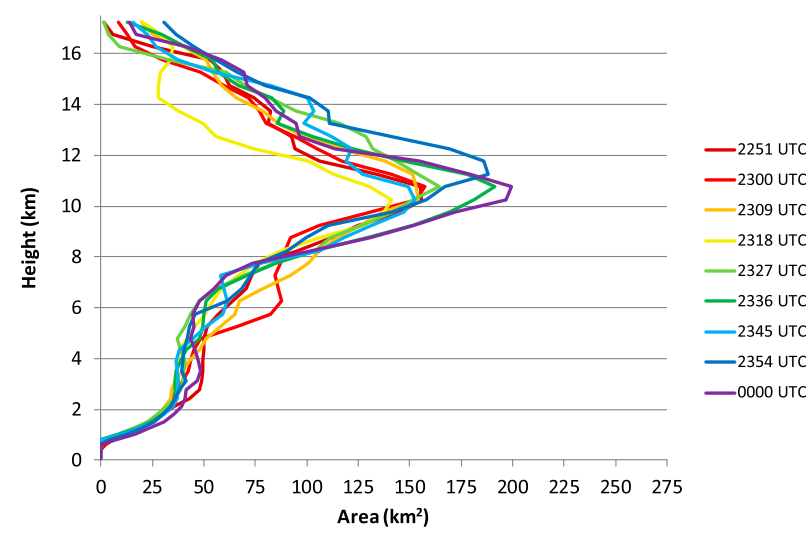

FIG. 7. Vertical profiles of updraft area for (a) OBS, (b) CNTRL 2134, (c) filtered CNTRL 0020, and (d) filtered BSS, where vertical velocity is at least $5 \mathrm{~m} \mathrm{~s}^{-1}$. Note that (c) has a larger range for the $x$ axis than the other panels.

and $12 \mathrm{~km}$ ) briefly exhibited a larger area of rotation around 2336, but were not sustained through 0000 . The lowest $2 \mathrm{~km}$ had a very subtle increase in the size of the mesocyclone between 2336 and 0000, consistent with previously noted low-level intensification (Figs. 4a, 6). While it is not known how the mesocyclone changed after 0000 , it should be noted that this storm did go on to produce a weak EF1 tornado at 0130 as a left-moving CL supercell converged with the Kingfisher storm (DiGangi et al. 2016). Thus, it appears that the observed changes in the near-storm environment worked to more strongly influence the size of the updraft (Figs. 7a, 8a), with more subtle shifts in the size of the mesocyclone itself (Fig. 9a), along with intensification (Figs. 4a, 6). In the simulations, trends are generally easier to discern. The mesocyclone in the CNTRL 2134 supercell rapidly diminished over time, consistent with its overall evolution (Figs. 2, 9b). Similarly, the significant growth and intensification of the CNTRL 0020 storm (Fig. 2) produced an associated expansion in vertical vorticity throughout much of the analysis period (Fig. 9c). In the BSS supercell, similar to the observations, the rotation area is fairly consistent, with a brief increase in size in the upper levels around 2345-2354. Even so, BSS exhibited a decrease in rotation area over time in the low levels (Fig. 9d), in contrast to the observations, further highlighting the fact that while BSS adds a notable degree of realism over fixed-sounding simulations, it is not able to fully replicate all observed features and trends due in part to predictability limitations (i.e., including, but not limited to, parameterization of the three-dimensional inflow environmental heterogeneity via continuous insertion of the three input soundings).

Much of the aforementioned trends are also evident in the time series of updraft and vertical vorticity volumes (Fig. 10). In the observations, the broad updraft and the core updraft significantly increase in volume throughout the analysis period; the broad updraft nearly doubles in volume from $\sim 1000$ to $2000 \mathrm{~km}^{3}$ (Fig. 10a), while the core updraft, even with the size fluctuations noted earlier 
a)

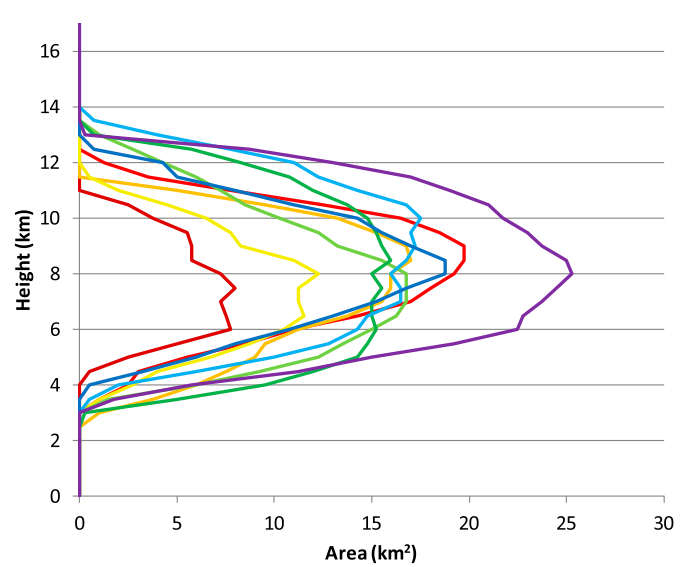

c)

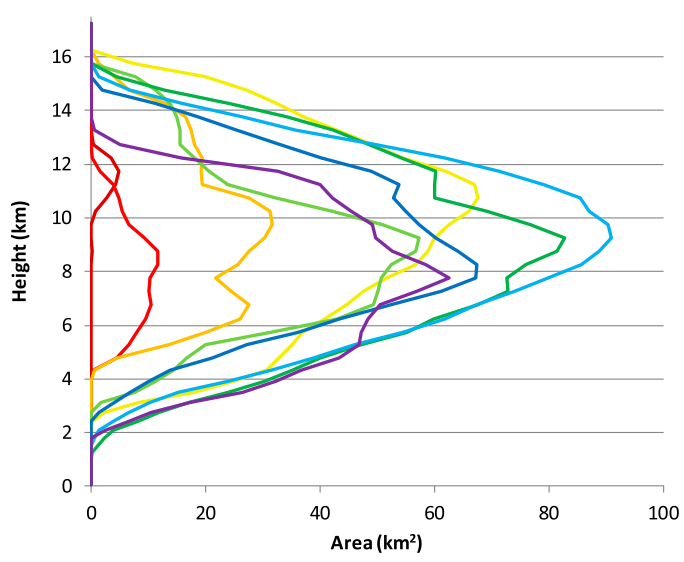

b)

CNTRL 2134

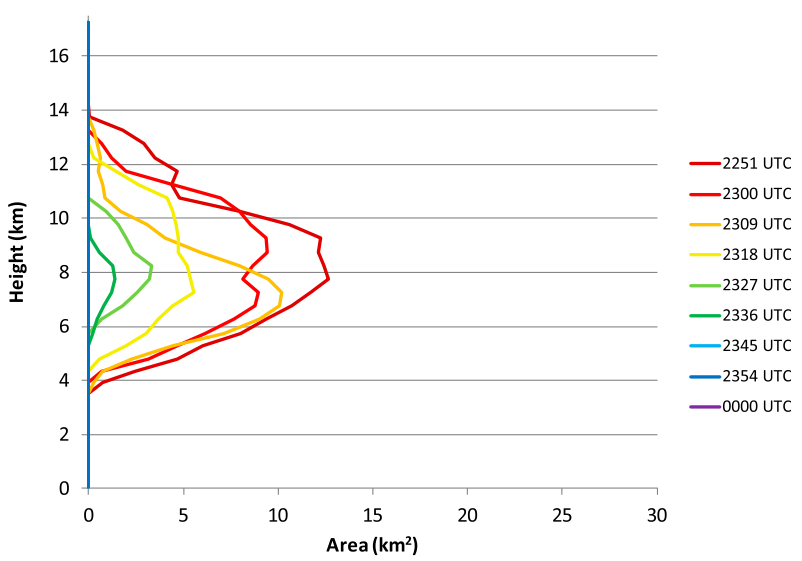

d)

Filtered BSS

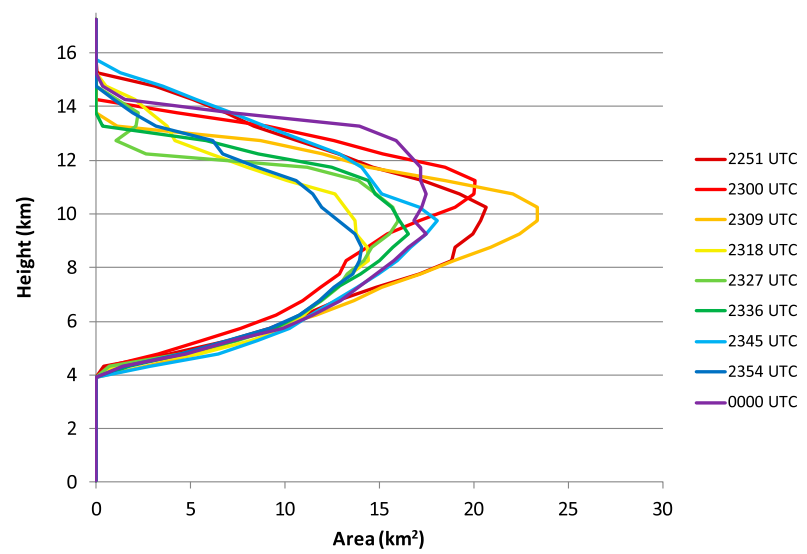

FIG. 8. As in Fig. 7, but for areas of vertical velocity of at least $30 \mathrm{~m} \mathrm{~s}^{-1}$.

(Fig. 8a), expands much more significantly from near $35 \mathrm{~km}^{3}$ at 2251 to $170 \mathrm{~km}^{3}$ at 0000 (Fig. 10b). Trends in the volumes of both CNTRL experiment updrafts plainly differ from the observations. CNTRL 2134 updrafts rapidly shrink over time and are essentially nonexistent by 2339, while CNTRL 0020 updrafts quickly expanded and sustained volumes much larger than the observations and other simulations (Figs. 10a,b). The BSS updraft volumes, while not a perfect reflection of the observations, demonstrated trends and volumetric magnitudes that were much more in line with the observations. For example, the broad updraft increased from $\sim 1200 \mathrm{~km}^{3}$ at 2251 to $\sim 1350 \mathrm{~km}^{3}$ at 0000 (admittedly a much smaller increase than the doubling evident in the observations; Fig. 10a), while the core updraft experiences no significant trend, sustaining a volume between $\sim 100$ and $130 \mathrm{~km}^{3}$ (magnitudes similar to the observations; Fig. 10b).

In the observations, the volume of the mesocyclone varies, yet broadly increases over time from $131 \mathrm{~km}^{3}$ at
2251 to $240 \mathrm{~km}^{3}$ at 0000 (Fig. 10c). Note that most of this growth occurs earlier in the analysis period, followed by both decreases and increases in volume, in line with earlier described various shifts in size (Fig. 9a). Similar to the updraft volumes, the CNTRL experiments demonstrate trends and magnitudes at odd with the observations. BSS, meanwhile, has a mesocyclone volume that, like the observations, largely increases through the analysis period $\left(380 \mathrm{~km}^{3}\right.$ at 2251 to $475 \mathrm{~km}^{3}$ at 0000$)$ with some variation in between (Fig. 10c). Thus, it is clear that the BSS simulation is an overall better reflection of the observed supercell trends, particularly in light of the markedly different evolution of the storms simulated in CNTRL 2134 and CNTRL 0020.

\section{Summary and conclusions}

Based on both subjective and objective measures, it is evident that BSS, using a temporally varying yet 
Vorticity area $>0.01 \mathrm{~s}^{-1}$

a)

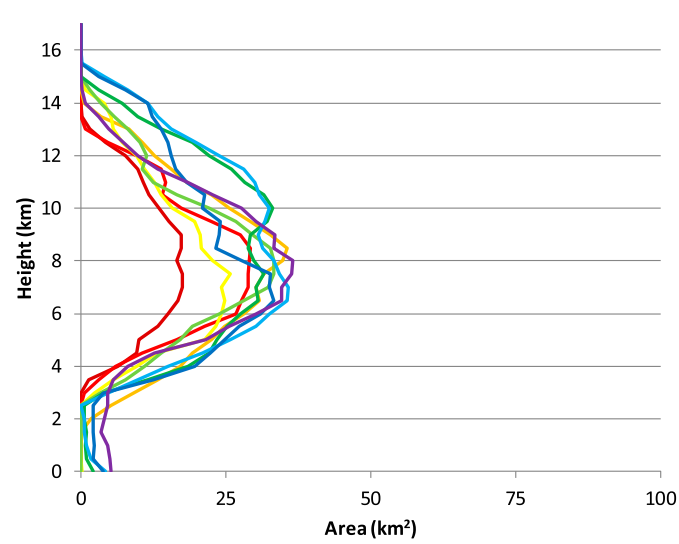

c)

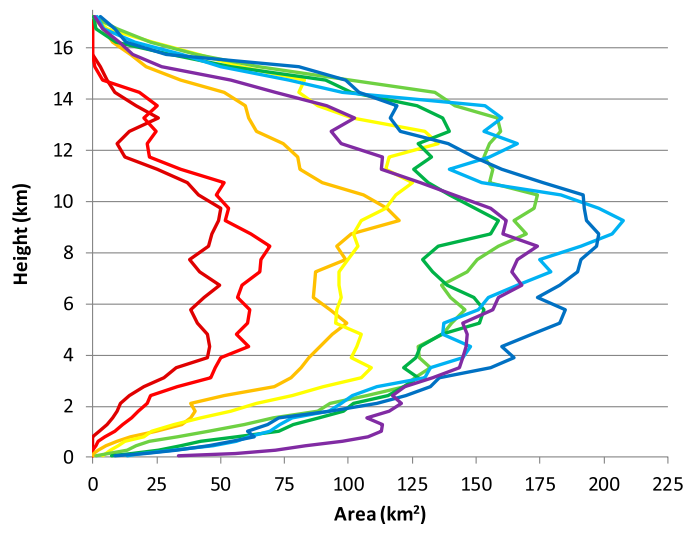

b)

CNTRL 2134

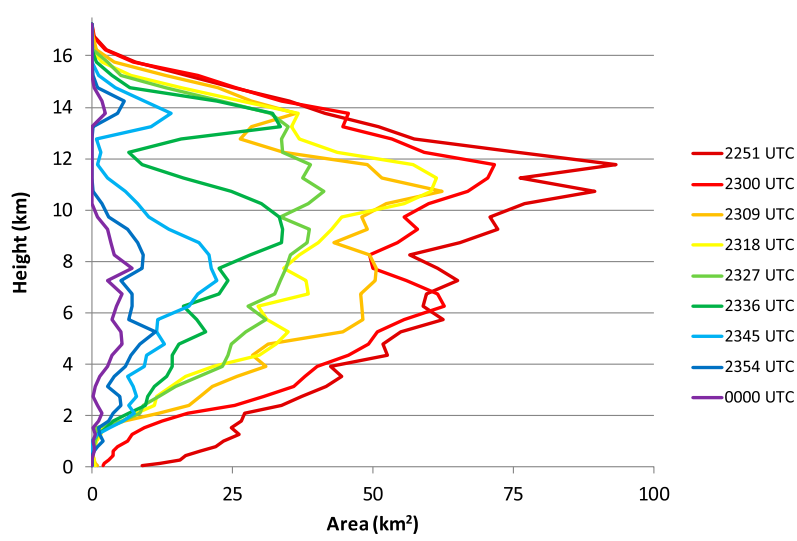

d)

Filtered BSS

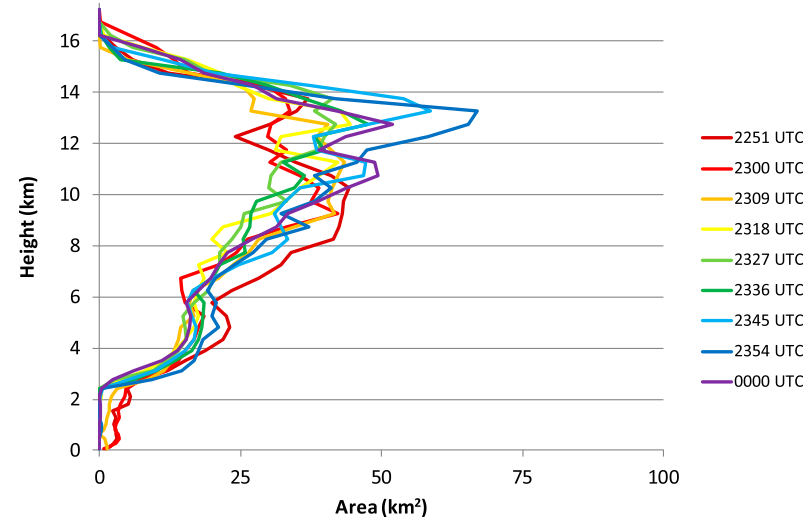

FIG. 9. As in Fig. 7, but for areas of vertical vorticity of at least $0.01 \mathrm{~s}^{-1}$.

horizontally homogeneous environment, was able to more realistically recreate the structure and evolution of the 29 May 2012 Kingfisher supercell in comparison to the fixed-environment experiments. The BSS supercell, while not an identical representation of the observed storm as evidenced by comparatively quasi-steady maximum intensity (Figs. 3, 4) and distributions of velocity and vorticity (Figs. 5, 6), did exhibit some similar characteristics. For example, the evolution in simulated reflectivity displayed increasing storm size and more intense reflectivities (Fig. 2), and trends in updraft and mesocyclone size and volume were largely consistent with the observations (Figs. 7-10). In sharp contrast to the observations, the two CNTRL simulations, with base-state environments fixed over time and space, failed to produce a long-lived, isolated, intensifying supercell; the CNTRL 2134 environment led to a weakening supercell dissipated during the analysis period, while the CNTRL 0020 environment, despite being the most favorable for strong, rotating convection, produced a supercell that rapidly evolved into an MCS (Fig. 2).

The marked disparity between the fixed and varying base-state simulations demonstrates that environmental variability played an important role in the convective evolution of the observed supercell, consistent with the results of previous studies (e.g., Ziegler et al. 2010; Davenport and Parker 2015b; Coffer and Parker 2015; Gropp and Davenport 2018). In the case of the Kingfisher storm, it appears that the significant increases in CAPE, shear, and SRH over time helped to support and further intensify the supercell following its initiation (Fig. 1). Importantly, it was necessary to incorporate the full scope of the environmental variability experienced by the storm into the base state, as single environments observed at any one point in the storm's lifetime were unable to sufficiently recreate the observed evolution.

It is clear that in this case, where most of the environmental variability experienced by the storm was temporal in nature, BSS does a better job (both 

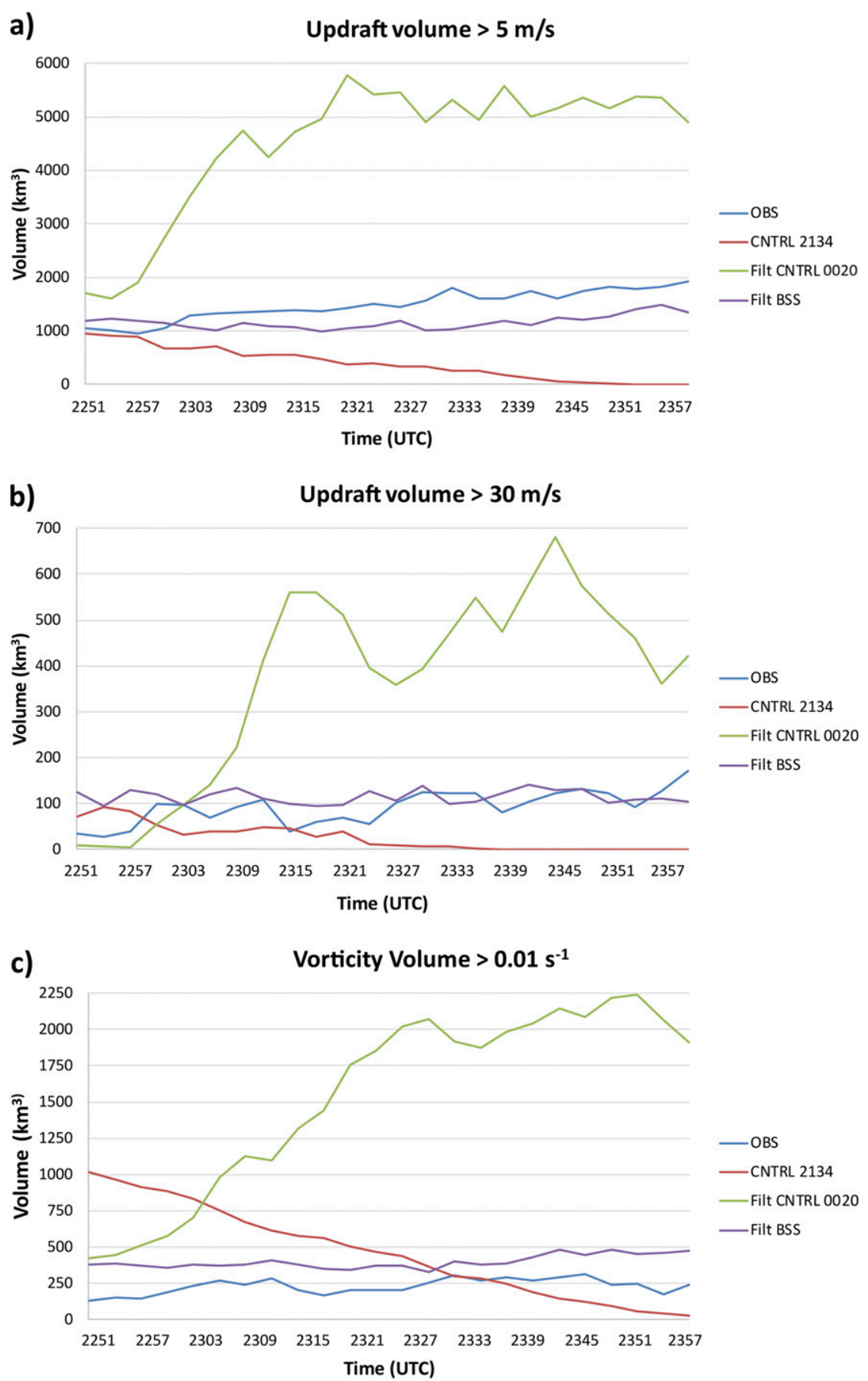

FIG. 10. Time series of (a) broad updraft volume (velocity $>5 \mathrm{~m} \mathrm{~s}^{-1}$ ), (b) core updraft volume (velocity $\left.>30 \mathrm{~m} \mathrm{~s}^{-1}\right)$, and (c) vertical vorticity volume (vorticity $>0.01 \mathrm{~s}^{-1}$ ).

qualitatively and quantitatively) of recreating storm structure and evolution than a single proximity sounding. Rather than attempting to select one "representative" sounding, a prospect that is particularly tricky for storms subject to significant temporal or spatial variability, BSS allows the model user to more realistically depict the environment and its effects on storm behavior without sacrificing any control over the simulation. Even so, this study is limited by its examination of a single case, which is not representative of the many types of environmental variability experienced by storms. For example, interaction with sharp spatial 
gradients in thermodynamic and kinematic quantities near-surface boundaries is often a catalyst for changes in storm intensity and behavior (e.g., Maddox et al. 1980; Markowski et al. 1998; Atkins et al. 1999; Fierro et al. 2006). It would be worthwhile to determine whether BSS can sufficiently represent the effects of surface boundaries by evaluating the extent to which storm modifications due to boundary interaction are sensitive to the physical presence of a boundary (i.e., the local horizontal heterogeneity and stratification as well as the accompanying circulation), as opposed to simply using a series of proximity soundings (with local fields assumed to be horizontally homogeneous) to serve as the spatial gradients. Such tests are planned for future study.

In scenarios where environmental variability is present, BSS is a simple yet effective tool that can reasonably recreate observed storm evolution in an idealized setting. Additional studies will be conducted using BSS to better understand how sensitive dynamical processes are to shifts in inflow environments, as well as additional investigation of the representativeness of the BSS approach.

Acknowledgments. The authors gratefully acknowledge George Bryan for his efforts in maintaining CM1, as well as the participants in the DC3 field campaign for their work in collecting the observed data. In particular, the authors also gratefully acknowledge guidance from Nenes Athanasios, Richard Moore, and Mary Barth about using the DC-8 in situ observations from DC3. Discussions with Ted Mansell about the NSSL twomoment microphysics scheme and aspects of implementing continuous BSS are also gratefully acknowledged. Support for the cited DC3 data collections were provided by NSF Grants AGS-10145102 and AGS-1063945 and by the National Severe Storms Laboratory (NSSL) Director's Discretionary Fund. The radar, sounding, mobile mesonet, and DC-8 data used for this study are available in the Earth Observing Laboratory 29 May 2012 DC3 Data Archive (Biggerstaff 2014a,b; Mansell 2014; Ziegler 2013, 2015; Chen and Olson 2018). Finally, comments from three anonymous reviewers provided valuable suggestions that significantly improved this manuscript.

\section{REFERENCES}

Atkins, N. T., M. L. Weisman, and L. J. Wicker, 1999: The influence of preexisting boundaries on supercell evolution. Mon. Wea. Rev., 127, 2910-2927, https://doi.org/10.1175/1520-0493(1999) 127<2910:TIOPBO>2.0.CO;2.

Barth, M. C., and Coauthors, 2015: The Deep Convective Clouds and Chemistry DC3 field campaign. Bull. Amer. Meteor. Soc., 96, 1281-1310, https://doi.org/10.1175/BAMS-D-13-00290.1.
Bela, M. M., and Coauthors, 2018: Effects of scavenging, entrainment, and aqueous chemistry on peroxides and formaldehyde in deep convective outflow over the Central and Southeast United States. J. Geophys. Res. Atmos., 123, 7594-7614, https://doi.org/10.1029/2018JD028271.

Betts, A. K., 1984: Boundary layer thermodynamics of a High Plains severe storm. Mon. Wea. Rev., 112, 2199-2211, https://doi.org/10.1175/1520-0493(1984)112<2199:BLTOAH> 2.0.CO;2.

Biggerstaff, M. I., 2014a: Mobile SMART radar-1 data, version 1.0. UCAR/NCAR-Earth Observing Laboratory, accessed 11 December 2018, http://data.eol.ucar.edu/dataset/353.216.

_ 2014b: Mobile SMART radar-2 data, version 1.0. UCAR/NCAREarth Observing Laboratory, accessed 11 December 2018, http://data.eol.ucar.edu/dataset/353.217.

— search and Teaching Radar: A collaboration to enhance research and teaching. Bull. Amer. Meteor. Soc., 86, 1263-1274, https://doi.org/10.1175/BAMS-86-9-1263.

Brooks, H. E., C. A. Doswell III, M. T. Carr, and J. E. Ruthford, 1996: Preliminary analysis of VORTEX-95 soundings. Preprints, 18th Conf. on Severe Local Storms, San Francisco, CA, Amer. Meteor. Soc., 133-136.

Bryan, G. H., and J. M. Fritsch, 2002: A benchmark simulation for moist nonhydrostatic numerical models. Mon. Wea. Rev., 130, 2917-2928, https://doi.org/10.1175/1520-0493(2002)130<2917: ABSFMN $>2.0 . C O ; 2$.

Bunkers, M. J., M. R. Hjelmfelt, and P. L. Smith, 2006: An observational examination of long-lived supercells. Part I: Characteristics, evolution, and demise. Wea. Forecasting, 21, 673-688, https://doi.org/10.1175/WAF949.1.

Burgess, D. W., E. R. Mansell, C. M. Schwarz, and B. J. Allen, 2010: Tornado and tornadogenesis events seen by the NOXP, Xband, dual-polarization radar during VORTEX2 2010. 25th Conf. on Severe Local Storms, Denver, CO, Amer. Meteor. Soc., 5.2, https://ams.confex.com/ams/25SLS/techprogram/ paper_176164.htm.

Chen, G., and J. Olson, 2018: NASA DC-8 1 Second Data Merge, version 6.0. UCAR/NCAR—Earth Observing Laboratory, accessed 21 March 2019, https://doi.org/10.5065/D6SF2TXB.

Coffer, B. E., and M. D. Parker, 2015: Impacts of increasing lowlevel shear on supercells during the early evening transition. Mon. Wea. Rev., 143, 19454-1969, https://doi.org/10.1175/ MWR-D-14-00328.1.

Crossett, C., 2017: An examination of the dynamics of a rear-inflow jet associated with an idealized mesoscale convective system. M.S. thesis, Dept. of Mathematical Sciences, University of Wisconsin-Milwaukee, $47 \mathrm{pp}$.

Davenport, C. E., and M. D. Parker, 2015a: Observations of the 9 June 2009 dissipating supercell from VORTEX2. Wea. Forecasting, 30, 368-388, https://doi.org/10.1175/WAF-D-14-00087.1.

- , and $-2015 \mathrm{~b}$ : Impact of environmental heterogeneity on the dynamics of a dissipating supercell thunderstorm. Mon. Wea. Rev., 143, 4244-4277, https://doi.org/10.1175/MWR-D-15-0072.1.

—, M. I. Biggerstaff, and C. L. Ziegler, 2017: Qualitative and quantitative comparisons of a base-state substitution simulation with dual-Doppler observations of the 29 May 2012 Kingfisher supercell. 17th Conf. on Mesoscale Processes, San Diego, CA, Amer. Meteor. Soc., 10.1, https://ams.confex.com/ ams/17MESO/webprogram/Paper319728.html.

Deardorff, J. W., 1980: Stratocumulus-capped mixed layer derived from a three-dimensional model. Bound.-Layer Meteor., 18, 495-527, https://doi.org/10.1007/BF00119502. 
DiGangi, E. A., D. R. MacGorman, C. L. Ziegler, D. Betten, M. Biggerstaff, M. Bowlan, and C. K. Potvin, 2016: An overview of the 29 May 2012 Kingfisher supercell during DC3. J. Geophys. Res. Atmos., 121, 14316-14343, https://doi.org/ 10.1002/2016JD025690.

Droegemeier, K. K., S. M. Lazarus, and R. Davies-Jones, 1993: The influence of helicity on numerically simulated convective storms. Mon. Wea. Rev., 121, 2005-2029, https://doi.org/ 10.1175/1520-0493(1993)121<2005:TIOHON>2.0.CO;2.

Fan, J., and Coauthors, 2017: Cloud-resolving model intercomparison of an MC3E squall line case: Part I-Convective updrafts. J. Geophys. Res. Atmos., 122, 9351-9378, https:// doi.org/10.1002/2017JD026622.

Fierro, A. O., and E. R. Mansell, 2017: Electrification and lightning in idealized simulations of a hurricane-like vortex subject to wind shear and sea surface temperature cooling. J. Atmos. Sci., 74, 2023-2041, https://doi.org/10.1175/JASD-16-0270.1.

_ M. S. Gilmore, E. R. Mansell, L. J. Wicker, and J. M. Straka, 2006: Electrification and lightning in an idealized boundarycrossing supercell simulation of 2 June 1995. Mon. Wea. Rev., 134, 3149-3172, https://doi.org/10.1175/MWR3231.1.

French, A. J., and M. D. Parker, 2008: The initiation and evolution of multiple modes of convection within a meso-alpha scale region. Wea. Forecasting, 23, 1221-1252, https://doi.org/10.1175/ 2008WAF2222136.1.

— mation following a squall line-supercell merger. Mon. Wea. Rev., 142, 4791-4822, https://doi.org/10.1175/MWRD-13-00356.1.

Gilmore, M. S., and L. J. Wicker, 1998: The influence of midtropospheric dryness on supercell morphology and evolution. Mon. Wea. Rev., 126, 943-958, https://doi.org/10.1175/15200493(1998)126<0943:TIOMDO>2.0.CO;2.

Graziano, T. M., and T. B. Carlson, 1987: A statistical evaluation of lid strength on deep convection. Wea. Forecasting, 2, 127-139, https://doi.org/10.1175/1520-0434(1987)002<0127:ASEOLS> 2.0.CO;2.

Gropp, M. E., and C. E. Davenport, 2018: The impact of the nocturnal transition on the lifetime and evolution of supercell thunderstorms in the Great Plains. Wea. Forecasting, 33, 1045-1061, https://doi.org/10.1175/WAF-D-17-0150.1.

Haltiner, G. J., and R. T. Williams, 1980: Numerical Prediction and Dynamic Meteorology. Wiley, $496 \mathrm{pp}$.

James, R. P., and P. M. Markowski, 2010: A numerical investigation of the effects of dry air aloft on deep convection. Mon. Wea. Rev., 138, 140-161, https://doi.org/10.1175/2009MWR3018.1.

Kain, J. S., and Coauthors, 2013: A feasibility study for probabilistic convection initiation forecasts based on explicit numerical guidance. Bull. Amer. Meteor. Soc., 94, 1213-1225, https:// doi.org/10.1175/BAMS-D-11-00264.1.

Klemp, J. B., R. B. Wilhelmson, and P. S. Ray, 1981: Observed and numerically simulated structure of a mature supercell thunderstorm. J. Atmos. Sci., 38, 1558-1580, https://doi.org/10.1175/ 1520-0469(1981)038<1558:OANSSO > 2.0.CO;2.

Ledoux, H., and C. Gold, 2005: An efficient natural neighbour interpolation algorithm for geoscientific modeling. Developments in Spatial Data Handling, P. F. Fisher , Ed., Springer, 97-108, https://doi.org/10.1007/3-540-26772-7_8.

Letkewicz, C. E., and M. D. Parker, 2010: Forecasting the maintenance of mesoscale convective systems crossing the Appalachian Mountains. Wea. Forecasting, 25, 1179-1195, https:// doi.org/10.1175/2010WAF2222379.1.
— A. J. French, and M. D. Parker, 2013: Base-state substitution: An idealized modeling technique for approximating environmental variability. Mon. Wea. Rev., 141, 3062-3086, https:// doi.org/10.1175/MWR-D-12-00200.1.

Loftus, A. M., D. B. Weber, and C. A. Doswell III, 2008: Parameterized mesoscale forcing mechanisms for initiating numerically simulated isolated multicellular convection. Mon. Wea. Rev., 136, 2408-2421, https://doi.org/10.1175/2007MWR2133.1.

Maddox, R. A., L. R. Hoxit, and C. F. Chappell, 1980: A study of tornadic thunderstorm interactions with thermal boundaries. Mon. Wea. Rev., 108, 322-336, https://doi.org/10.1175/15200493(1980)108<0322:ASOTTI $>2.0 . C O ; 2$.

Mansell, E. R., 2014: Mobile National Severe Storm Laboratory (NSSL) NOAA NOXP radar data in DORADE format, version 1.0. UCAR/NCAR-Earth Observing Laboratory, accessed 11 December 2018, http://data.eol.ucar.edu/dataset/353.215.

— , and C. L. Ziegler, 2013: Aerosol effects on simulated storm electrification and precipitation in a two-moment bulk microphysics model. J. Atmos. Sci., 70, 2032-2050, https://doi.org/ 10.1175/JAS-D-12-0264.1.

_ - — , and E. C. Bruning, 2010: Simulated electrification of a small thunderstorm with two-moment bulk microphysics. J. Atmos. Sci., 67, 171-194, https://doi.org/10.1175/ 2009JAS2965.1.

Markowski, P., and Y. Richardson, 2007: Observations of vertical wind shear heterogeneity in convective boundary layers. Mon. Wea. Rev., 135, 843-861, https://doi.org/10.1175/MWR3334.1.

Markowski, P. M., E. N. Rasmussen, and J. M. Straka, 1998: The occurrence of tornadoes in supercells interacting with boundaries during VORTEX-95. Wea. Forecasting, 13, 852-859, https:// doi.org/10.1175/1520-0434(1998)013<0852:TOOTIS >2.0.CO;2.

Parker, M. D., 2008: Response of simulated convective squall lines to low-level cooling. J. Atmos. Sci., 65, 1323-1341, https:// doi.org/10.1175/2007JAS2507.1.

, 2014: Composite VORTEX2 supercell environments from near-storm soundings. Mon. Wea. Rev., 142, 508-529, https:// doi.org/10.1175/MWR-D-13-00167.1.

Potvin, C. K., L. J. Wicker, and A. Shapiro, 2012: Assessing errors in variational dual-Doppler wind syntheses of supercell thunderstorms observed by storm-scale mobile radars. J. Atmos. Oceanic Technol., 29, 1009-1025, https://doi.org/10.1175/ JTECH-D-11-00177.1.

Rasmussen, E. N., and J. M. Straka, 1998: Variations in supercell morphology. Part I: Observations of the role of upper-level storm-relative flow. Mon. Wea. Rev., 126, 2406-2421, https:// doi.org/10.1175/1520-0493(1998)126<2406:VISMPI >2.0.CO;2.

Richardson, Y. P., K. K. Droegemeier, and R. P. Davies-Jones, 2007: The influence of horizontal environmental variability on numerically simulated convective storms. Part I: Variations in vertical shear. Mon. Wea. Rev., 135, 3429-3455, https://doi.org/ 10.1175/MWR3463.1

Rotunno, R., and J. B. Klemp, 1982: The influence of the shearinduced pressure gradient on thunderstorm motion. Mon. Wea. Rev., 110, 136-151, https://doi.org/10.1175/1520-0493(1982) $110<0136$ :TIOTSI $>2.0$.CO;2.

— supercell storms. J. Atmos. Sci., 42, 271-292, https://doi.org/ 10.1175/1520-0469(1985)042<0271:OTRAPO > 2.0.CO;2.

Varble, A., and Coauthors, 2014: Evaluation of cloud-resolving and limited area model intercomparison simulations using TWPICE observations: 1. Deep convective updraft properties. J. Geophys. Res. Atmos., 119, 13 891-13 918, https://doi.org/ 10.1002/2013JD021371 
Wade, A. R., M. C. Coniglio, and C. L. Ziegler, 2018: Comparison of near- and far-field supercell inflow environments using radiosonde observations. Mon. Wea. Rev., 146, 2403-2315, https://doi.org/10.1175/MWR-D-17-0276.1.

Weisman, M. L., and R. Rotunno, 2000: The use of vertical wind shear versus helicity in interpreting supercell dynamics. J. Atmos. Sci., 57, 1452-1472, https://doi.org/10.1175/15200469(2000)057<1452:TUOVWS >2.0.CO;2.

Wipf, J., and A. J. French, 2014: Simulated effects of an isolated supercell on the evolution of a nearby squall line. 27th Conf. on Severe Local Storms, Madison, WI, Amer. Meteor. Soc., 55, https:// ams.confex.com/ams/27SLS/webprogram/Paper253967.html.

Yang, Q., and Coauthors, 2015: Aerosol transport and wet scavenging in deep convective clouds: A case study and model evaluation using a multiple passive tracer analysis approach. J. Geophys. Res. Atmos., 120, 8448-8468, https://doi.org/ 10.1002/2015JD023647.

Yurchak, B. S., 2013: An assessment of radiosonde launch conditions affected by the surface wind. Russ. Meteor. Hydrol., 38, 159-167, https://doi.org/10.3103/S1068373913030035.

Yuter, S. E., and R. A. Houze Jr., 1995: Three-dimensional kinematic and microphysical evolution of Florida cumulonimbus. Part II: Frequency distributions of vertical velocity, reflectivity, and differential reflectivity. Mon. Wea. Rev., 123, 1941-1963, https://doi.org/10.1175/1520-0493(1995)123<1941: TDKAME $>2.0 . \mathrm{CO} ; 2$.

Ziegler, C. L., 1999: Issues in forecasting mesoscale convective systems: An observational and modeling perspective. Storms, R. Pielke Jr. and R. Pielke Sr., Eds., Vol. 2, Routledge Press, $26-42$.

_- 2013: NSSL MGAUS Oklahoma-Texas Sounding data, version 1.0. UCAR/NCAR-Earth Observing Laboratory, accessed 11 December 2018, http://data.eol.ucar.edu/ dataset/353.105

_ , 2015: NSSL Oklahoma Mobile Mesonet Meteorological Data, version 1.0. UCAR/NCAR-Earth Observing Laboratory, accessed 21 March 2019, https://data.eol.ucar.edu/ dataset/353.218.

— and E. N. Rasmussen, 1998: The initiation of moist convection at the dryline: Forecasting issues from a case study perspective. Wea. Forecasting, 13, 1106-1131, https://doi.org/ 10.1175/1520-0434(1998)013<1106:TIOMCA>2.0.CO;2.

_ , E. R. Mansell, J. M. Straka, D. R. MacGorman, and D. W. Burgess, 2010: The impact of spatial variations of low-level stability on the lifecycle of a simulated supercell storm. Mon. Wea. Rev., 138, 1738-1766, https://doi.org/10.1175/2009MWR3010.1. 